\title{
Synthesis and elaboration of trans 2,3-diaryloxiranes
}

\author{
Carlo Bonini and Paolo Lupattelli* \\ Dipartimento di Chimica, Università degli Studi della Basilicata, via N. Sauro 85, 85100 \\ Potenza, Italy \\ E-mail:paolo.lupattelli@unibas.it
}

This manuscript is dedicated to Dr. Arlette Solladié-Cavallo on the occasion of her 70th anniversary

\begin{abstract}
2,3-Diaryloxiranes represent challenging intermediates for both their preparation and synthetic elaboration. Provided their synthesis in enantiopure form, they can be considered as suitable starting material for the synthesis of functionalized 1,2-diarylethanols, which are easily found in chiral auxiliaries, ligands and organocatalysts. The most efficient asymmetric methods for their preparation and synthetic elaboration are herein described. Regio- and stereoselective ring opening reactions, as reduction, nucleophilic opening with halides and oxygen nucleophiles have allowed straightforward access to versatile chiral intermediates such as aniline alcohols, halohydrins and 1,3-dioxolanes, their transformation affords chiral bases and bi- or tridentate ligands to use in asymmetric synthesis.
\end{abstract}

Keywords: Diaryloxiranes, asymmetric epoxidation, ring opening reaction, aniline alcohols, halohydrins, 1,3-dioxolanes

\section{Contents}

1. Synthesis of 2,3-Diaryloxiranes

1.1 Epoxidation of stilbene type olefins

1.1.1 Metal catalysed epoxidation

1.1.2 Epoxidation by dioxiranes

1.2 Epoxidation of carbonyl compounds

1.2.1 Stoichiometric ylide-mediated epoxidation

1.2.2 Catalytic ylide-mediated epoxidation

2. Elaboration of 2,3-Diaryloxiranes

2.1 Reductive ring opening 
2.3 Nucleophilic ring opening by metal halides

2.4 Ring opening by oxygen nucleophiles

\section{Introduction}

Epoxides are among the most intriguing and challenging moieties in organic synthesis because they are not only significant synthetic endpoints, ${ }^{1}$ but also highly useful synthetic intermediates. Due to their strain ring (having a thermodynamic driving force usually greater than $20 \mathrm{kcal} / \mathrm{mol}$ ), they are considered "spring loaded" for nucleophilic ring opening reactions and among the best candidates for click chemistry. ${ }^{2}$ Utility and convenience of their use can be enhanced by the modulation of their reactivity with the help of Lewis acids coordinating the oxygen atom. Thus, ring-openings of epoxides have been applied in industrial scale for the synthesis of bulk chemicals, and in the synthesis of natural products and pharmaceuticals. A wide range of nucleophiles are described to react efficiently with epoxides and the regioselectivity of the opening is usually predicted by the different electrophilicity of the two oxiranyl carbons and/or the formation of chelates in presence of other coordinating moieties in the molecule. The high stereoselectivity in the opening reaction is mostly assured by the $\mathrm{S}_{\mathrm{N}} 2$ pathway and there is usually low, if any, epimerization at the electrophilic oxiranyl carbon. Such general stereospecificity highly encourages the use of enantiopure epoxides as key intermediates in asymmetric synthesis, since no loss of enantiomeric purity in the subsequent steps is generally reported. One of the major advantages of nucleophilic openings of three member rings is stereoelectronically disfavored competing elimination process. ${ }^{3}$

The importance of all these procedures lies not only in the synthesized product, but also in the availability of the starting materials. Usually, epoxides are easily prepared by oxidation process of the corresponding alkenes and many enantioselective versions of this reaction have been developed.

2,3-Diaryloxiranes can be considered non conventional epoxides in terms of their synthesis and, above all, their reactivity. The classical metal-catalyzed epoxidation of olefins and, in general, any oxidative procedure is usually slower in the case of stilbene compounds and high HOMO aromatic $\pi$-systems (as in polyphenolic stilbenes) are hardly preserved in presence of strong oxidants. Compared to alkyl ones, 2,3-diaryloxiranes usually show lower reactivity towards nucleophiles and they need some activation by Lewis acid. Due to the characteristic chemical behavior of benzyl type carbons in neutral or acidic medium they appear challenging substrates for the little reactivity differences of the two oxiranyl carbons and the possible side reactions such as eliminations or rearrangements.

This report deals with the most efficient methods of preparation and opening reactions of optically active 2,3-diaryloxiranes and their applications in the synthesis of key enantiopure intermediates. 


\section{Synthesis of 2,3-diaryloxiranes}

\subsection{Epoxidation of stilbenic olefins}

Since of the Sharpless epoxidation reaction of allylic alcohols many efforts have been done to discover a more general protocol which might be effective for the asymmetric epoxidation of unfunctionalized olefins. Chiral metal complexes were found firstly to effect highly enantioselective oxo-transfer to unfunctionalized olefins, as mimic the stereoselectivity found in biological systems. ${ }^{4}$ In the last decade chiral dioxiranes have been developed as effective epoxidation catalysts and have expanded the range of the substrate requirement in many cases. ${ }^{5}$

This paragraph presents an overview of the most efficient methods of epoxidation of stilbene olefins, and shows the scope, advantages and limitation of this approach.

\subsubsection{Metal catalysed epoxidations}

Oxo transfer from metal complexes results in a net two electron reduction at the metal center. Thus, iron, manganese, ruthenium and chromium have proven effective for catalytic epoxidation via oxo-transfer, ${ }^{6}$ and these metals are mostly coordinated by tetradentate porphyrin and salen ligands. The lack of stereospecificity in the epoxidation of certain olefins gives evidence for a stepwise oxo-transfer mechanism competing with the direct attack with concerted C-O bond formation. Alkyl-substituted olefins generally undergo stereospecific epoxidation, with cisolefins affording cis-epoxides exclusively. Acyclic olefins conjugated to aryl, vinyl, or alkynyl groups undergo nonstereospecific epoxidation, with cis-olefins affording mixtures of cis and trans epoxides. Non-polar radical intermediates are involved in the case of non-concerted epoxidation with $\mathrm{Mn}$ (salen) catalysts. ${ }^{7}$ Among these complexes, catalyst 1 (Figure 1) has been employed widely on both laboratory and industrial scale for the epoxidation of cis-disubstituted and trisubstituted olefins. ${ }^{8}$ trans-olefins remain particularly challenging substrates for asymmetric epoxidation with oxo-transfer catalyst. However, catalysts bearing stereogenic centers on the 3- and 3'-positions of the salen ligand, as in 2 and 3 have been examined, with a promising $61 \%$ ee in the epoxidation of trans-stilbene (by catalyst 2 ). ${ }^{9}$
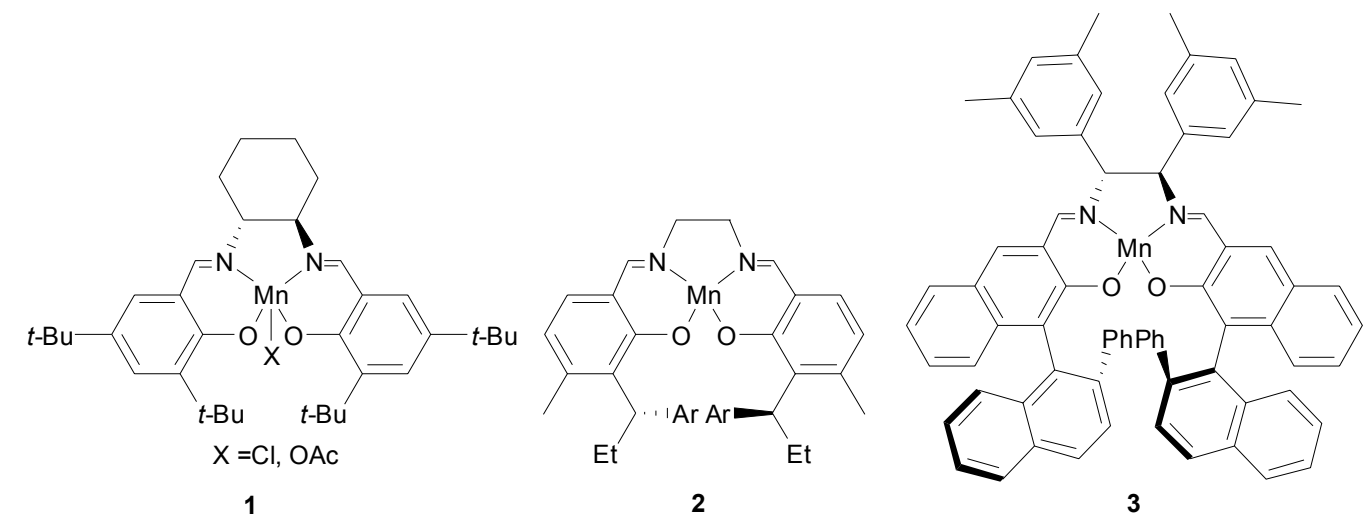

Figure 1 
Excellent selectivity $(>90 \% e e)$ has been obtained for aryl- or alkynyl-substituted terminal-, cis-disubstituted-, and trisubstituted olefins with the second generation catalysts (as $3^{10}$ ), whereas trans-disubstituted olefins were epoxidized with low rates and low ees $(<40 \%)$.

A more successful strategy for the enantioselective synthesis of trans-epoxides has been developed with the [Mn(salen)]-catalyzed epoxidation of cis-disubstituted olefins in the presence of alkaloid-derived phase transfer catalysts such as 5 (Scheme 1). In this case the reaction resulted in the formation of the trans epoxide as the major, and in some cases nearly exclusive, product. ${ }^{11}$

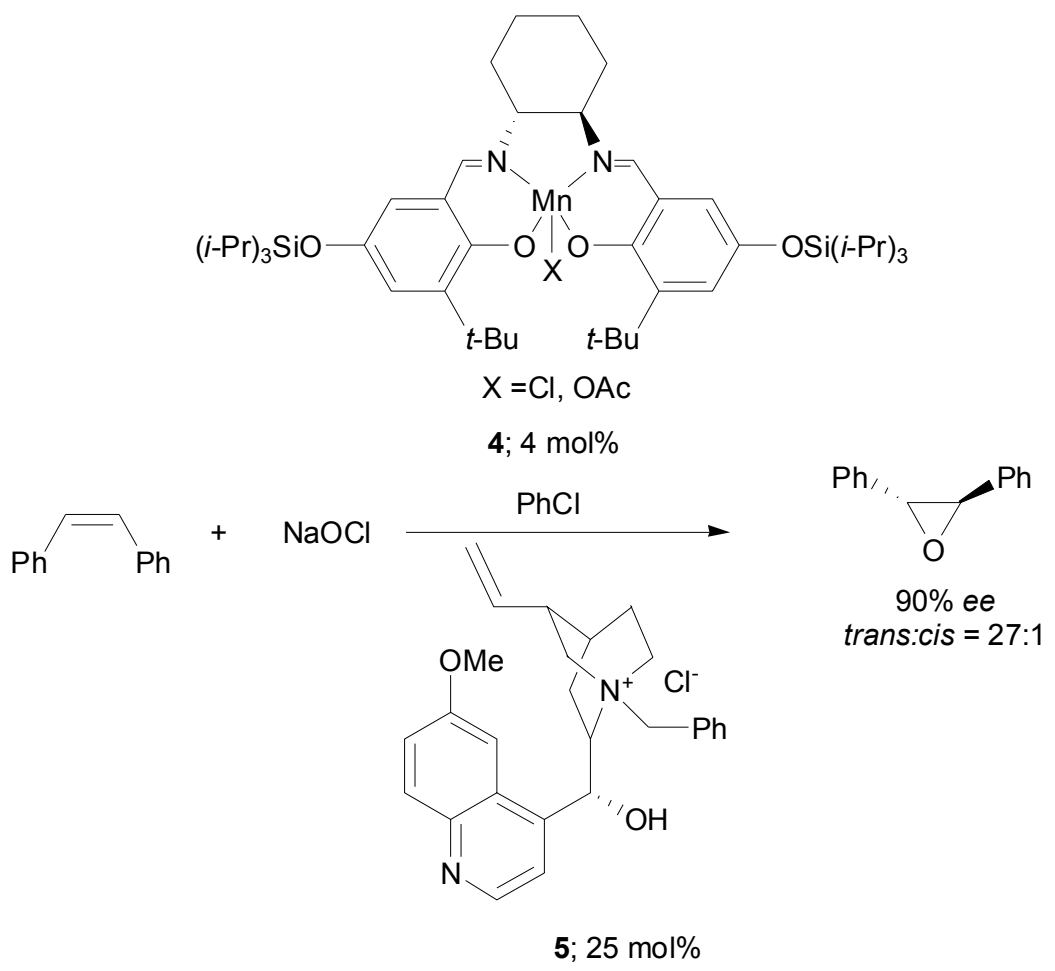

\section{Scheme 1}

Recently, three novel chiral binuclear Mn(III)-Schiff-base complexes have been synthesized and used in the asymmetric epoxidation of trans-stilbene. The best result was obtained using $\mathbf{6 c}$ and $\mathrm{NaClO}$ as terminal oxidant ( $43 \%$ yield, $40 \%$ ee $){ }^{12}$ 


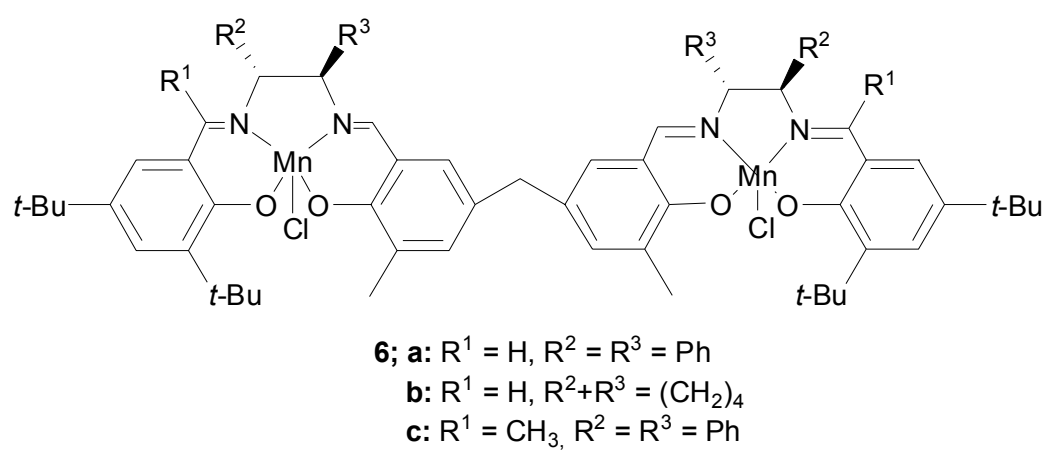

Figure 2

Even lower ees (3-12\%) were obtained if using such dimeric complexes in the presence of pyridine $N$-oxide or Fujita's porous coordination polymer $\left(\left\{\left[\mathrm{Cd}\left(4,4^{\prime}-\text { bpy }\right)_{2}\left(\mathrm{NO}_{3}\right)_{2}\right\}_{\infty}\right) .{ }^{13}\right.$ Analogous chromium-salen systems appear complementary to their manganese counterpart, since good enantioselectivity was obtained in the epoxidation of the "difficult" transdisubstituted olefins. Chromium oxo complexes as $\mathbf{8}$, derived from the parent salen complexes 7 (Figure 3) are isolable and have been studied deeply in both stoichiometric and catalytic epoxidations.

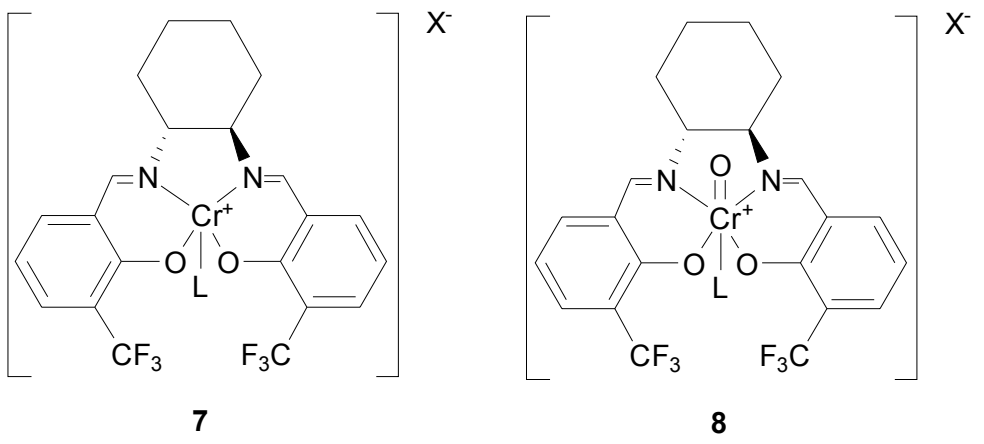

\section{Figure 3}

These chiral chromium $(\mathrm{V})$ catalysts have shown good enantioselectivity in the epoxidation of trans-disubstituted olefins, as in the case of trans- $\beta$-methylstyrene, in which the corresponding epoxide was obtained in $45 \%$ yield and in $92 \%$ ee, by use of stoichiometric quantity of $7\left(\mathrm{X}^{-}=\right.$ $\left.\mathrm{NO}_{3}{ }^{-}, \mathrm{L}=\mathrm{Ph}_{3} \mathrm{PO}\right)$ and 1.2 equivalents of iodosyl benzene. Under catalytic conditions (10 mol\% of 7) in the presence of $\mathrm{PhIO}$, the epoxide was formed in higher yield (71\%) but with a slightly lower ee (82\%). ${ }^{14}$

Many others metals, ligands and terminal oxidants have been used to broaden the scope of the reaction, but examples of metal catalysed asymmetric epoxidation of stilbene type olefins are only occasionally described in the literature. ${ }^{15}$ Ruthenium catalysts based on pyridine-2,6bisoxazoline (pybox) ligands, as 9 (Scheme 2), have been used in combination with iodosyl 
benzene, bisacetoxyiod benzene [PhI(OAc) $)_{2}$, or TBHP for the oxidation of trans stilbene. In the best results, with $\mathrm{PhI}(\mathrm{OAc})_{2}$ as oxidant, trans-stilbene oxide was obtained in $80 \%$ yield and with $63 \%$ ee. ${ }^{16}$ Such catalytic system was also reexamined, finding that asymmetric epoxidations could be performed even with $30 \%$ aqueous hydrogen peroxide.

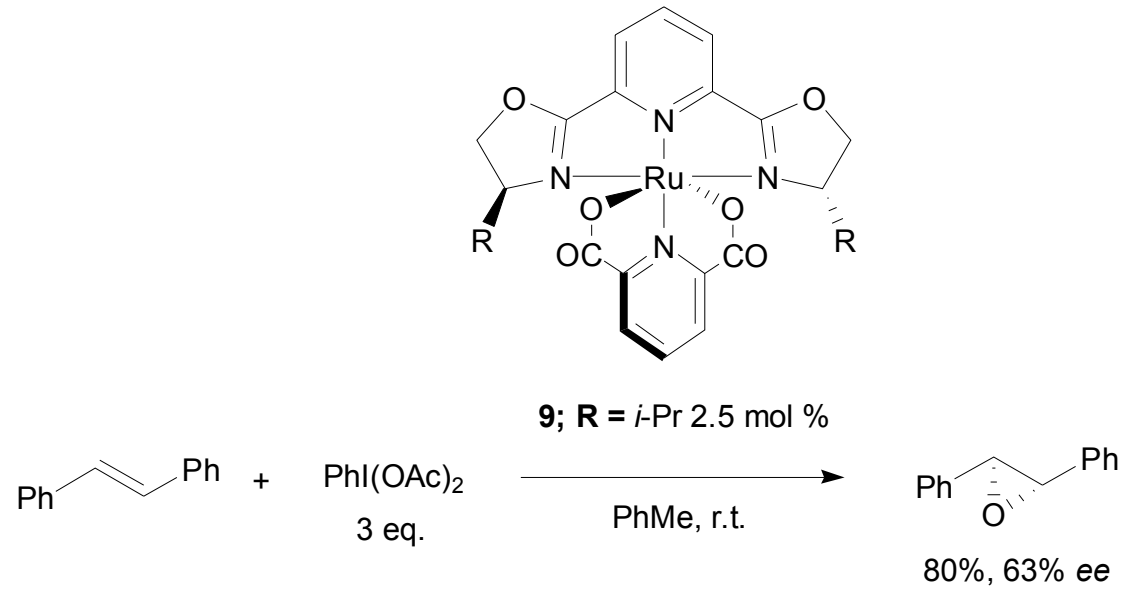

\section{Scheme 2}

More than 30 different [Ru-(pybox)(pydic)] 10 and [Ru(pyboxazine)(pydic)] 11 complexes (Scheme 3) have been tested in the asymmetric epoxidation of styrene and trans-stilbene.

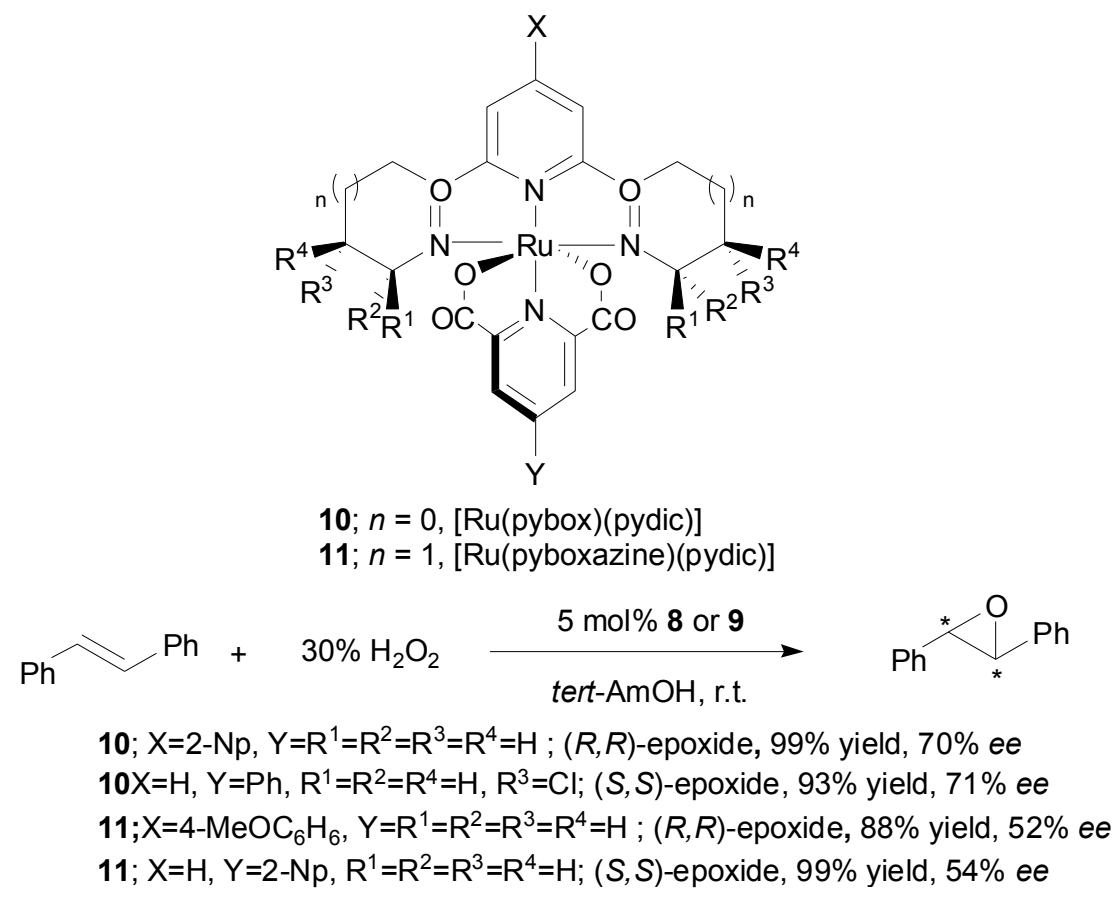

\section{Scheme 3}


The yields were from good to excellent in all cases and exploiting the broad coverage of substitution pattern of the ligands, both enantiomers of trans-stilbene oxide could be obtained, with ees ranging from $52 \%$ to $71 \% .{ }^{17}$ More easily tunable $N, N, N$-pyridinebisimidazoline (pybim) ligands 12 (Figure 4) have also been synthesized and tested as ruthenium complexes, giving excellent yields and moderate to good enantioselectivities in the epoxidation of aromatic olefins (up to $71 \%$ ee for trans-stilbene oxide). ${ }^{18}$

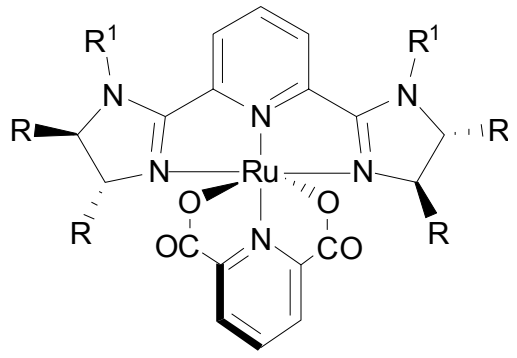

12

\section{Figure 4}

\subsubsection{Epoxidation by dioxiranes}

The oxidation of organic compounds with dioxirane reagents has emerged since late ' 80 as an important synthetic method. Currently, chiral dioxiranes, derived in situ from the oxidation of suitable chiral ketones by the triple salt oxone $\left(2 \mathrm{KHSO}_{5} \cdot \mathrm{KHSO}_{4} \cdot \mathrm{K}_{2} \mathrm{SO}_{4}\right)$, have emerged as some of the most effective organocatalysts in the asymmetric epoxidation of alkenes. ${ }^{19}$ Excellent enantioselectivity has been achieved with trisubstituted and trans-alkenes, while moderate to good selectivity has been achieved for other alkenes, thus making this method complementary to the metal catalyzed epoxidation. The discovery that ketones bearing electron-withdrawing groups such as halogen and OAc adjacent to the carbonyl showed higher activity in epoxidation reactions led to design $\mathrm{C}_{2}$-symmetric ketones as $\mathbf{1 3}$ which effected the catalytic epoxidation of unfunctionalized olefins with high level of enantioselectivity in the case of stilbene derivatives (Scheme 4). ${ }^{20}$ 

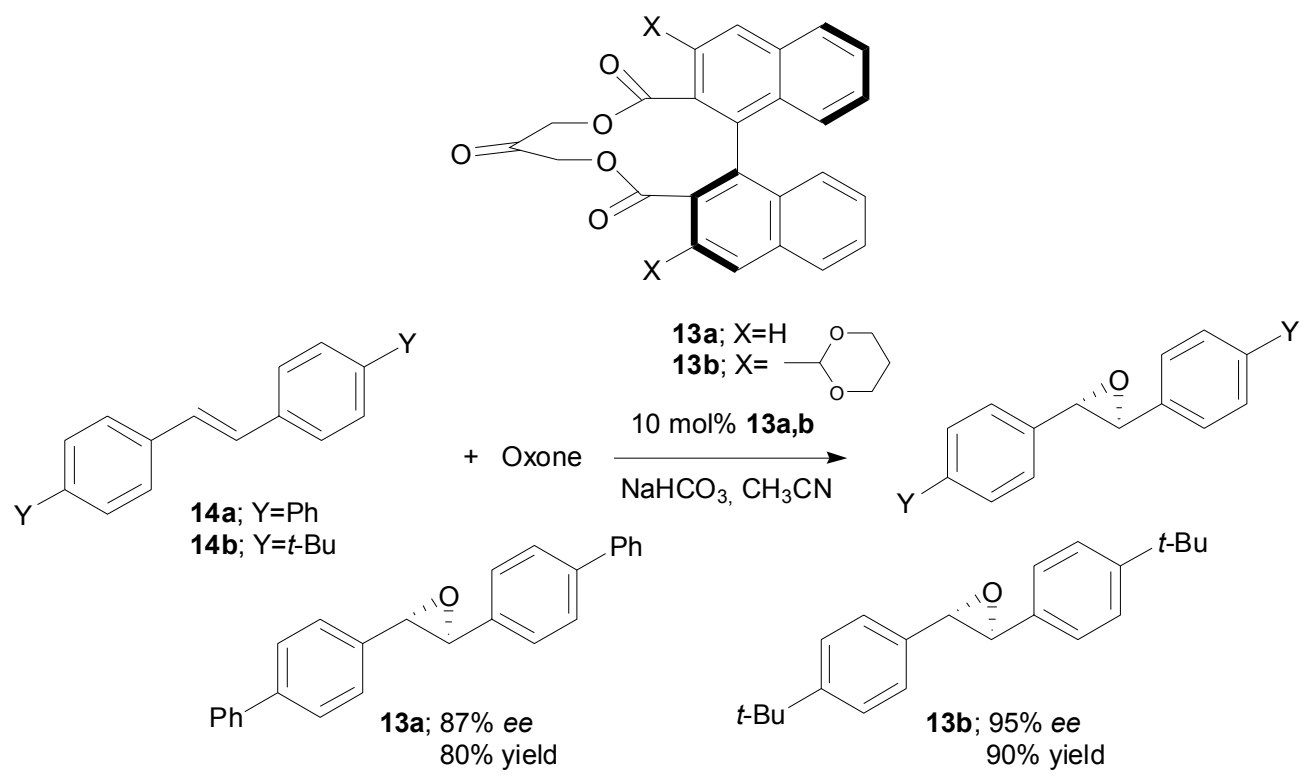

\section{Scheme 4}

The fructose-derived ketone 15 (Shi's ketone) was discovered to be particularly effective for the epoxidation of trans-olefins (Scheme 5). Trans-stilbene was epoxidized in 95\% ee using stoichiometric amount of ketone. ${ }^{21}$ The method has been rendered catalytic $(30 \% \mathrm{~mol})$ upon the discovery that higher $\mathrm{pH}$ led to improved substrate conversion. ${ }^{22}$
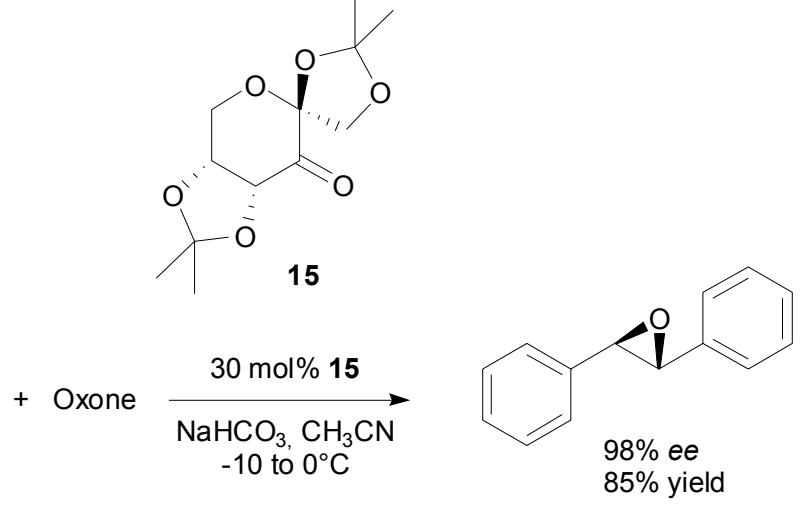

\section{Scheme 5}

The discovery of the activating effect of a single fluorine atom adjacent to carbonyl in the dioxirane-mediated epoxidation of olefins has widened the choice of enantiopure ketone potential catalysts, which could be suitable dioxirane precursors. Thus, many structurally different chiral fluoroketones have been prepared and successfully tested to trans olefins. Fluoro tropanone ammonium triflate 16 slowly converted trans-stilbene to the corresponding $(S, S)$ - 
epoxide in $79 \%$ yield and $58 \%$ ee, while $\mathrm{C}_{2}$ biphenyl cyclic fluoro ketone $\mathbf{1 7}$ gave $(R . R)$-epoxide in $46 \%$ yield and $94 \%$ ee (Figure 5 ). ${ }^{23}$

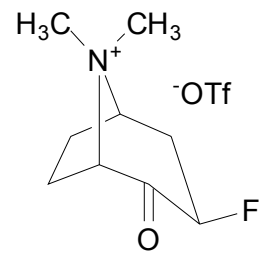

16

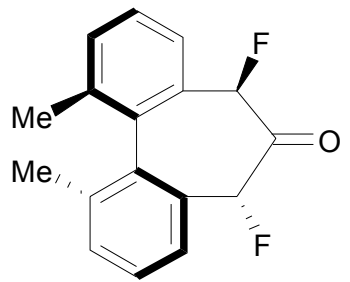

17

Figure 5

Armstrong has studied different chiral fluorinated bicyclo[3.2.1]octan-3-ones, as $\mathbf{1 8}$ and $\mathbf{1 9}$ (Figure 6), which gave high yields and good enantioselectivities. ${ }^{24} \alpha$-fluorotropinone 18 has been also supported on silica materials and its activity appeared comparable to that of homogenous counterpart, $^{25}$ while 2,2- and 2,4-disubstituted derivatives of 8oxabicyclo[3.2.1] octan-3-one 18 afford the epoxide in lower yield. ${ }^{26}$

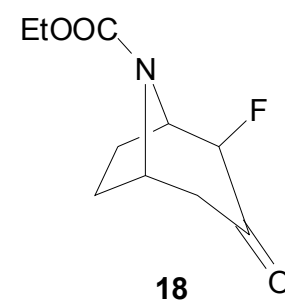

trans-stilbene $76 \%$ ee $(R, R)$

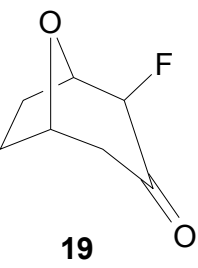

trans-stilbene $83 \%$ ee $(R, R)$

\section{Figure 6}

Solladié-Cavallo's studies on $\alpha$-fluorocyclohexanones derived from chiral pool have introduced efficient and easy-to-make enantiopure fluoroketones, which worked well in catalytic amounts and gave among the highest enantioselectivities in the epoxidation of trans-olefins. C8substituted ketones 20-23 (Figure 7) provided enantioselectivity ranging between 82 and 90\%, ${ }^{27}$ while unsubstituted ketone $\mathbf{2 4}$ gave only $60 \%$ ee in the case of trans-stilbene epoxidation. ${ }^{28}$ 


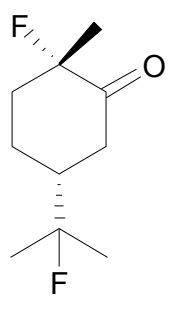

20

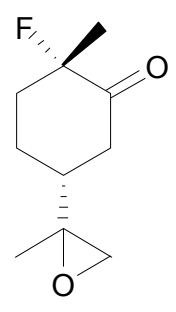

21

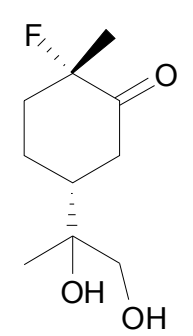

22

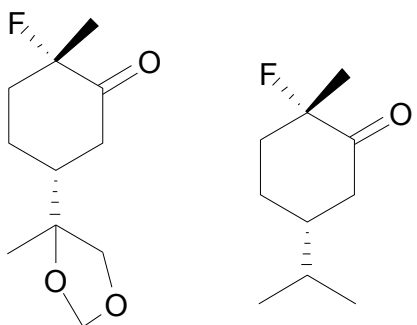

24

23

\section{Figure 7}

\subsection{Epoxidation of carbonyl compounds}

There are two general approaches to the direct asymmetric epoxidation of carbonyl compounds: ylide-mediated epoxidation and $\alpha$-halo enolate epoxidation (Darzens reaction). While the latter has been successfully used for the synthesis of epoxy esters, the first has shown particularly useful for the preparetion of 2,3-diaryloxiranes (Scheme 6).

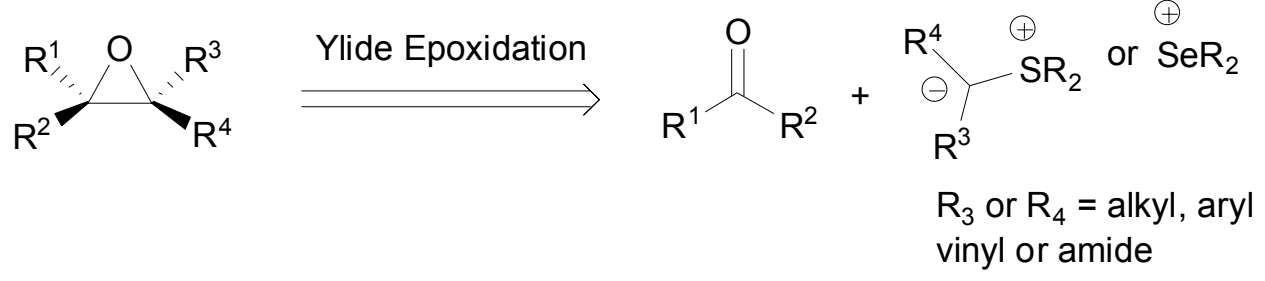

\section{Scheme 6}

\subsubsection{Stoichiometric ylide-mediated epoxidation}

Solladié-Cavallo's group has successfully used Eliel's oxathiane 25 (derived from pulegone in three steps) in asymmetric epoxidation (Scheme 7). ${ }^{29}$

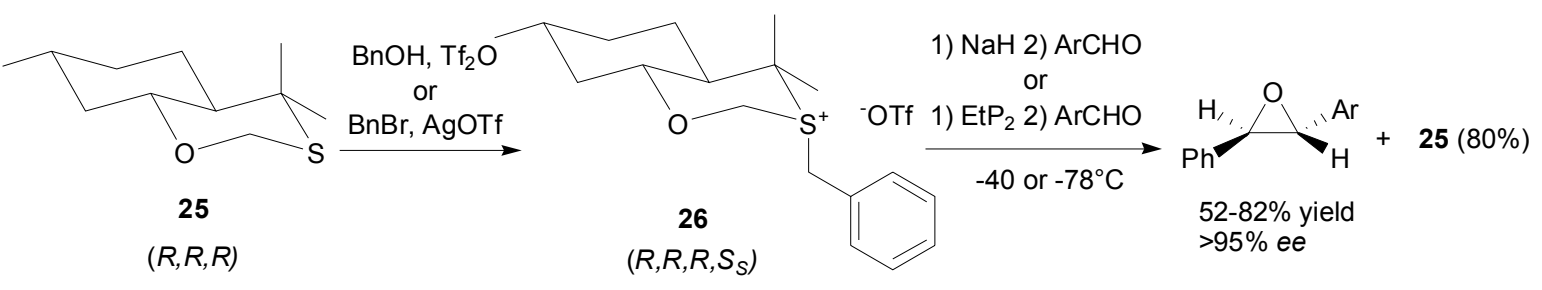

\section{Scheme 7}

This sulfide was initially benzylated to form a single diastereoisomer of the sulfonium salt 26. The corresponding ylide was formed by the aid of sodium hydride and the epoxidation was carried out at low temperature to afford trans-diaryl epoxides $\mathbf{2 7}$ with good stereoselctivity and 
high enantioselectivity with recovery of the chiral sulfide $\mathbf{2 5}$. The use of a phosphazene base $\left(\mathrm{EtP}_{2}\right)$ resulted in rapid ylide formation and allowed the preparation of aryl-vinyl epoxides ${ }^{30}$ and heteroaromatic aryl-epoxides ${ }^{31}$ in good chemical yield and high stereo- and enantioselectivity. Such procedure has been used for the synthesis of different substituted trans-2,3-diaryloxiranes (vide infra), proving its high versatility.

The Aggarwal group has used chiral sulfide 28, derived from camphorsulfonyl chloride, in asymmetric epoxidation. Once preformed the salt 29 from either the bromide or the alcohol, the ylide was prepared using different bases in presence of a range of carbonyl compounds. The method proved effective for the synthesis of aryl-aryl, aryl-heteroaryl, aryl-alkyl, and aryl-vinyl epoxides $^{32}$ (Scheme 8).

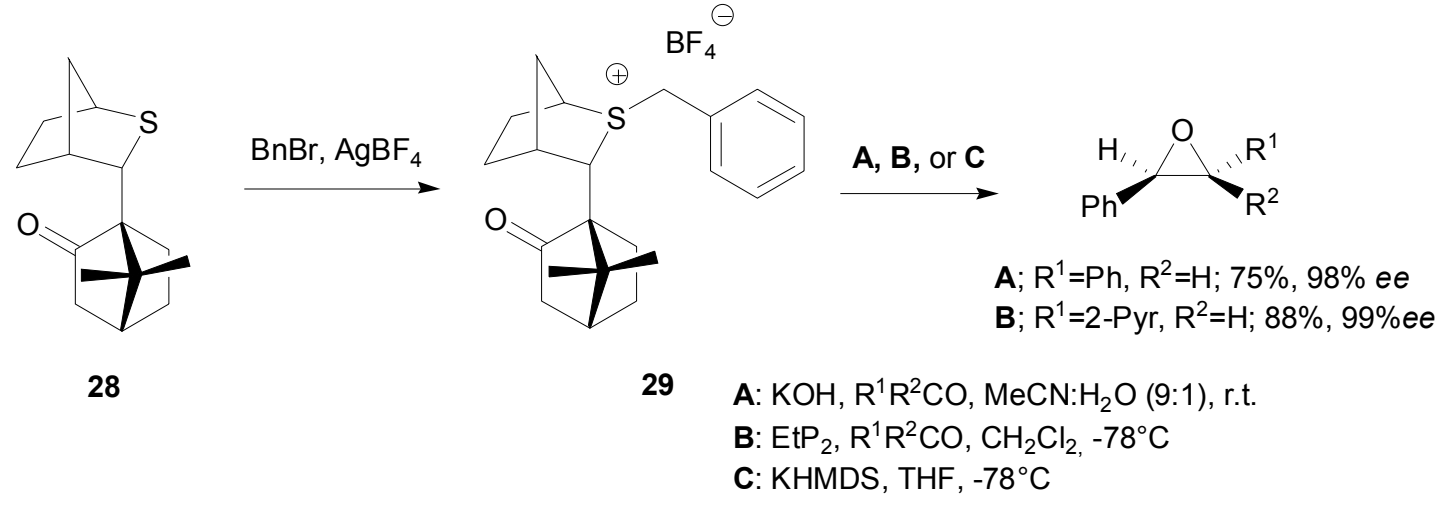

\section{Scheme 8}

\subsubsection{Catalytic ylide-mediated epoxidation}

Many efforts have been made to render the ylide-mediated epoxidation catalytic. Aggarwal has developed an efficient catalytic cycle, in which the sulfur ylide is generated through the reaction between chiral sulfide $\mathbf{2 8}$ and a metallocarbene. The metallocarbene is generated by the decomposition of a diazo compound 32, which can in turn be generated in situ from the tosylhydrazone salt $\mathbf{3 1}$ by warming in the presence of phase transfer catalyst. The tosylhydrazone salt can also be generated in situ from the corresponding aldehyde $\mathbf{3 0}$ and tosylhydrazine in presence of base (Scheme 9). 


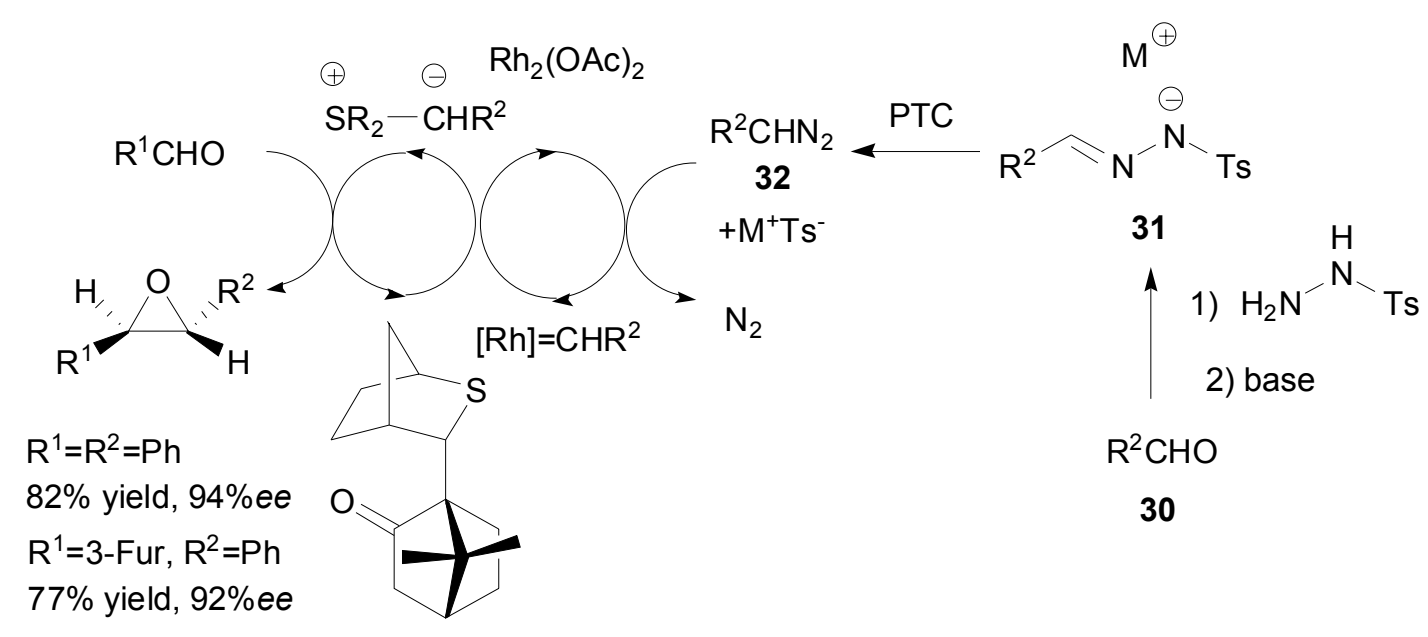

28

\section{Scheme 9}

This process enables the coupling of two different aldehydes to produce trans-epoxides in high enantio- and diastereoselectivity. A range of aldehydes have been used in this process with phenyl tosylhydrazone salt and good selectivity was observed with aromatic and heteroaromatic aldehydes. ${ }^{33}$ Pyridyl aldehydes proved to be incompatible with this process, presumably due to the presence of a nucleophilic nitrogen atom, which can compete with the sulfide for the metallocarbene to form a pyridinium ylide. Sulfide loadings as low as $5 \mathrm{~mol} \%$ could be used in many cases. Benzaldehyde was also treated with a range of tosylhydrazone salts and the scope of the process has been extensively mapped out, enabling the optimum disconnection for epoxidation to be chosen.

\section{Elaboration of 2,3-diaryloxiranes}

Among the various methods for the preparation of a single enantiomer, asymmetric catalysis represents the most attractive method from the atom-economy point of view. Chiral ligands play a fundamental role in the complex phenomenon of asymmetric catalysis. Among the possible key intermediates for the synthesis of functionalized alcohols, epoxides are considered the most versatile and convenient, due to their well known enantioselective preparation methods and regioselective ring opening and subsequent protections. ${ }^{34}$ In recent years, our research group has started a study on regio- and stereoselective ring opening reactions on 2,3-diaryloxiranes, with the aim to afford, in a simple and immediate way, functionalized 1,2-diarylethanols, which are found in chiral auxiliaries, ligands and stationary phases for chiral HPLC. Moreover, the contemporary presence of two aromatic rings promotes non covalent $\pi-\pi$ interactions, which are more and more studied because they are involved in a wide variety of chemical and biological processes. ${ }^{35}$ Despite the high chemical versatility of such epoxides, literature data on their use 
are few, probably due to the difficulty of obtaining efficient regioselective ring openings on epoxide benzylic carbons which have very similar reactivity. Our study allowed to individuate original and efficient synthetic procedures of regio- and stereoselective ring opening reactions on such substrates, obtaining new enantiopure aniline aminoalcohols and benzoxazines, 1,2diarylbromo alcohols and acetonides.

\subsection{Reductive ring opening}

The reductive ring-opening of epoxides to the corresponding alcohols has become a powerful tool in organic synthesis, due to the rapid development of efficient and practical methods for their preparation, both in racemic and in enantiopure form. Metal hydrides ${ }^{36}$ or dissolving metals are frequently employed for this purpose, although the large quantity of metal sludge are often produced. ${ }^{37}$ The need of a practical version of this reaction with low environmental impact has generated interest in heterogeneous catalytic systems. In particular, various catalysts based on $\mathrm{Ni}, \mathrm{Pd}$ and Pt has been developed in order to increase the chemo- and regioselectivity of such reactions, even with enantiopure epoxides. ${ }^{38}$ Different hydrogen sources, such as $\mathrm{HCOONH}_{4},{ }^{39}$ and catalysts, such as $\mathrm{Pd} / \mathrm{C}$ ethylendiamine complexes, ${ }^{40}$ have been used to improve selectivity and to prevent further hydrogenolysis of the alcoholic C-O bond. Nevertheless, the solvolysis with methanol remains a problem, particularly with benzylic epoxides. Recently, Pd nanoparticles, microencapsulated in polyurea, have been described to be very efficient in the reductive ring-opening of different benzyl and alkyl epoxides. ${ }^{41}$ Moreover, a magnetically separable palladium catalyst has been synthesized and described to be active and selective for hydrogenolysis of different epoxides. ${ }^{42}$ Titanocene(III) chloride has been claimed to be one of the best reagent reported carrying out the reductive epoxide opening. ${ }^{43}$ The $\beta$-titanoxy radicals have been reduced efficiently by different hydrogen atom donors and the regioselectivity towards the less-substituted alcohol has been reported to be high. ${ }^{44}$

Chiral pyridyl alcohols have numerous applications, as ligands in asymmetric metal catalysis, ${ }^{45}$ as resolving agents ${ }^{46}$ or as starting materials for the preparation of more advanced chiral ligands. ${ }^{47}$ As one of the first applications of the asymmetric synthesis of diaromatic epoxides, with high stereo- and enantioselectivity, Solladié-Cavallo described the reductive ring opening of 2-pyridyl epoxide 33a and 2-furyl epoxide 34 (Scheme 10). Asymmetric synthesis of the epoxides was successfully performed by using the pure benzylsulfonium salt derived from Eliel's oxathiane, the corresponding commercial 2-pyridyl- and 2-furylaldehyde and the phosphazene base $\mathrm{EtP}_{2}{ }^{31}$ 


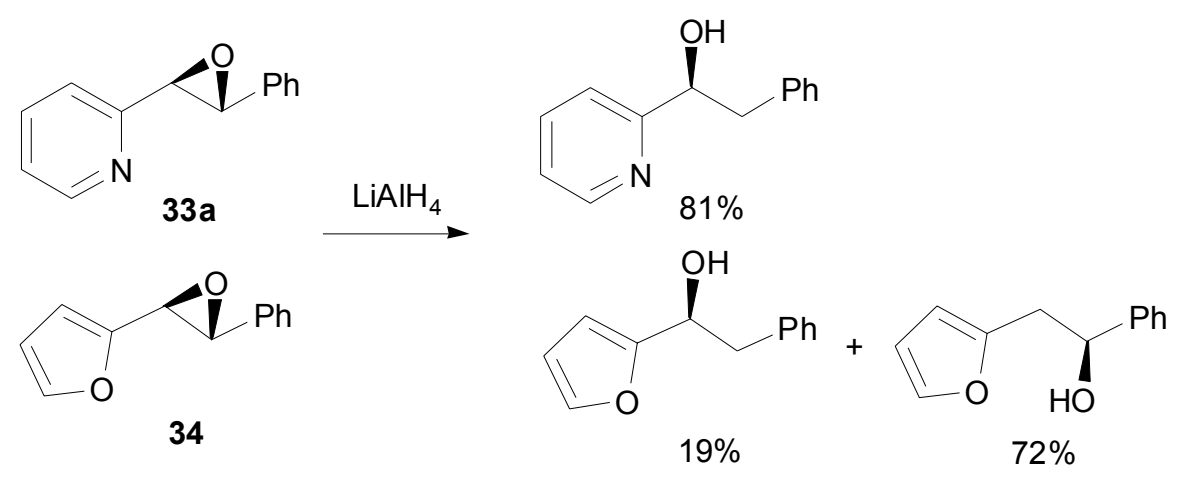

\section{Scheme 10}

These first results have stimulated the interest in searching a general regioselective reductive opening method for nonsymmetrical substituted 2,3-diaryloxiranes. A series of ortho and para monosubstituted trans 2,3-diaryloxiranes 33 have been prepared in racemic form (scheme 11) and tested with various reductive agents.

$$
\mathrm{PhCH}_{2} \mathrm{Cl}+\left(\mathrm{CH}_{3}\right)_{2} \mathrm{~S} \stackrel{\mathrm{H}_{2} \mathrm{O}}{\longrightarrow} \mathrm{PhCH}_{2} \mathrm{~S}^{+}\left(\mathrm{CH}_{3}\right)_{2} \mathrm{Cl}
$$

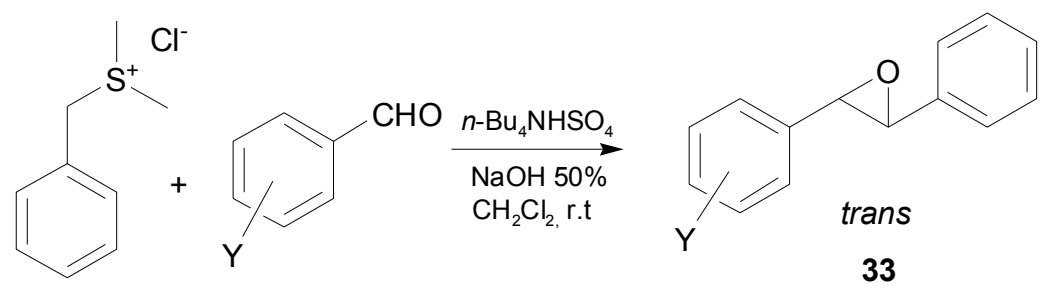

\section{Scheme 11}

Although catalytic hydrogenation over $\mathrm{Pd} / \mathrm{C}$ is one of the most simple and clean reduction procedure, in terms of reagents and subsequent work up, it is only occasionally described to be efficient on epoxides. ${ }^{48}$ Moreover, no systematic study on 2,3-diaryloxiranes are known so far. Thus, the epoxides of type $\mathbf{3 3}$ were reacted with $\mathrm{H}_{2}$ at $1 \mathrm{~atm}$ in presence of catalytic amount of $\mathrm{Pd} / \mathrm{C} 10 \%$ in the appropriate solvent. The most significant results are collected in Table $1 .{ }^{49}$ 
Table 1. Catalytic hydrogenation of trans non symmetrical 2,3-substituted oxiranes

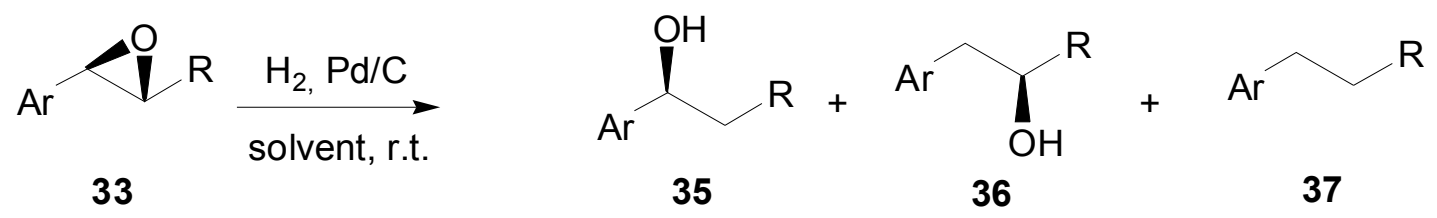

\begin{tabular}{|c|c|c|c|c|c|c|c|c|}
\hline Entry $^{\mathrm{a}}$ & Epox. & $\mathrm{Ar}$ & $\mathrm{R}$ & Solv. $^{\mathrm{b}}$ & Time (h) & $35^{\mathrm{c}}(\%)$ & $36^{\mathrm{c}}(\%)$ & $37(\%)$ \\
\hline 1 & 33a & 2-pyridyl & $\mathrm{Ph}$ & A & 2 & 90 & - & - \\
\hline 2 & 33b & 4-pyridyl & $\mathrm{Ph}$ & A & 2 & 90 & - & - \\
\hline 3 & 33c & $4-\mathrm{OCH}_{3} \mathrm{Ph}$ & $\mathrm{Ph}$ & B & 7 & 80 & 12 & - \\
\hline 4 & 33d & $2-\mathrm{CF}_{3} \mathrm{Ph}$ & $\mathrm{Ph}$ & B & 2 & $70^{\mathrm{d}}$ & - & - \\
\hline 5 & 33d & $2-\mathrm{CF}_{3} \mathrm{Ph}$ & $\mathrm{Ph}$ & A & 3 & 60 & - & 40 \\
\hline 6 & $33 \mathbf{e}$ & $4-\mathrm{CF}_{3} \mathrm{Ph}$ & $\mathrm{Ph}$ & B & 2 & 60 & - & 40 \\
\hline 7 & $33 e$ & $4-\mathrm{CF}_{3} \mathrm{Ph}$ & $\mathrm{Ph}$ & A & 3 & 50 & - & 50 \\
\hline 8 & $33 f$ & 4-FPh & $\mathrm{Ph}$ & A & 3 & $70^{\mathrm{c}}$ & - & - \\
\hline 9 & $33 \mathrm{~g}^{\mathrm{e}}$ & $\mathrm{Ph}$ & $\mathrm{CH}_{3}$ & $\mathrm{~A}$ & 2 & - & 95 & - \\
\hline
\end{tabular}

${ }^{\mathrm{a}}$ All reactions were performed using $\mathrm{Pd}, \mathrm{C}(10 \%) / \mathrm{substrate}=20 \mathrm{mg} / \mathrm{mmol}$. The conversions were all higher than $99 \%$ and were determined by ${ }^{1} \mathrm{H}$ NMR of the crude product. ${ }^{\mathrm{b}} \mathrm{A}=\mathrm{CH}_{3} \mathrm{OH}$; $\mathrm{B}=$ EtOAc, $1 \% \mathrm{AcOH}^{\mathrm{c}}$ Isolated yield. ${ }^{\mathrm{d}}$ No isolable product was obtained from the rest of the crude. ${ }^{\mathrm{e}}$ Epoxide 33g was prepared by oxidation of commercial trans $\beta$-methyl-styrene with $m$-CPBA.

All reactions were completely regioselective, producing only one of the two possible regioisomers, with chemical yields from good to excellent. Such regioselectivity appeared puzzling, being irrespective to the substituent electronic properties.

In fact, from all the oxiranes with either a strong electron-withdrawing group (33a, 33b, 33d and 33e) or an electron-releasing group (33c) on one phenyl ring, the regioisomer of type 35 was isolated as the major product in the reaction mixture. Even with the weak electron-releasing $p$ fluoro substituent, the same behavior was confirmed (entry 8). These results were quite surprising, if we consider the classical mechanism of hydrogenolysis, with benzyl type radicals as key intermediates. In fact none of the results seemed to suggest the formation of a regular $S$ type benzyl radical, ${ }^{50}$ which should be the substituted one in all cases affording the opposite regioisomer.

The next step of our study was to test reductive ring opening of diaryl epoxides by hydrides, in order to induce a change of regioselectivity. Among various hydrides which are efficient in the reductive opening of epoxides, $\mathrm{LiAlH}_{4}$ is the most common, ${ }^{51}$ and the milder borohydrides often require the presence of a Lewis acid, which activates the epoxide toward nucleophilic attack. Indeed, $\mathrm{NaBH}_{4} / \mathrm{ZrCl}_{4}{ }^{52}$ or $\mathrm{Zn}\left(\mathrm{BH}_{4}\right)_{2} / \mathrm{SiO}_{2}{ }^{53}$ systems are described to be efficient and, recently, $\mathrm{NaCNBH}_{3}$ in presence of $\mathrm{ZnI}_{2}$ was found to produce regioselective ring opening of benzylic epoxides. ${ }^{54} \mathrm{NaBH}_{4} / \mathrm{Pd}$ system proved to be highly dependent upon reaction conditions, ranging between a simple source of hydrogen (like in the catalytic hydrogenation) and a more "hydridic" 
reagent in selective nitro group reactions. ${ }^{55}$ This suggested to test it with diarylepoxides, looking for a complementary method with respect to catalytic hydrogenation. Thus, the epoxides $\mathbf{3 3}$ were treated with $\mathrm{NaBH}_{4} / \mathrm{Pd}$ and the most significant results are collected in Table 2.

Table 2. Reduction of epoxides by $\mathrm{NaBH} 4 / \mathrm{Pd}$ system

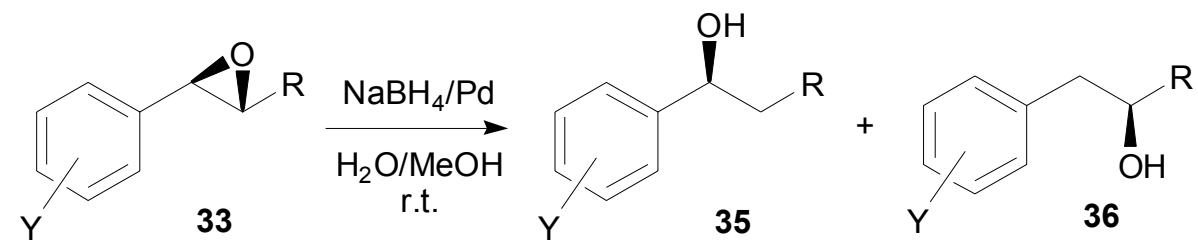

\begin{tabular}{ccccccc}
\hline Entry $^{\mathrm{a}}$ & Epox. & $\mathrm{Ar}$ & $\mathrm{R}$ & Time $(\mathrm{h})$ & $\mathbf{3 5}^{\mathrm{b}}(\mathbf{\%})$ & $\mathbf{3 6}^{\mathrm{b}}(\mathbf{\%})$ \\
\hline 1 & 33a & 2-pyridyl & $\mathrm{Ph}$ & 4 & - & 80 \\
2 & 33b & 4-pyridyl & $\mathrm{Ph}$ & 4 & - & 75 \\
3 & 33c & $4-\mathrm{OCH}_{3} \mathrm{Ph}$ & $\mathrm{Ph}$ & 12 & $70^{\mathrm{c}}$ & - \\
4 & 33d & $2-\mathrm{CF}_{3} \mathrm{Ph}$ & $\mathrm{Ph}$ & 2 & 90 & - \\
5 & 33e & $4-\mathrm{CF}_{3} \mathrm{Ph}$ & $\mathrm{Ph}$ & 3 & $65^{\mathrm{c}}$ & - \\
6 & $\mathbf{3 3 g}$ & $\mathrm{Ph}$ & $\mathrm{CH}_{3}$ & 12 & - & 90 \\
\hline
\end{tabular}

${ }^{\mathrm{a}}$ All the reactions were performed at r.t., with $\mathrm{NaBH}_{4} /$ substrate $=7.5 / 1.0, \mathrm{Pd} / \mathrm{C}(10 \%) /$ substrate $=$ $10 \mathrm{mg} / \mathrm{mmol}$. The conversions were all higher than $99 \%$ and were determined by ${ }^{1} \mathrm{H}$ NMR of the crude product. ${ }^{\mathrm{b}}$ Isolated yield. ${ }^{\mathrm{c}} \mathrm{No}$ isolable product was obtained from the rest of the crude.

The regioselectivity was highly affected by substituents electronic properties, combined with the unique characteristic of the reagent. Indeed, ortho and para substituted substrates gave the same regioisomer, in similar chemical yield. In substrates with the strong electron withdrawing group $\mathrm{CF}_{3}$ (entry 4 and 5), only the regioisomer 35 were detected in the reaction mixture, the attack of the hydrogen being exclusively on the $\beta$-carbon with respect to the substituted phenyl ring. These results account for an electron deficient acyclic intermediate, which was already postulated for opening reaction with $\mathrm{LiBr} / \mathrm{Amb} .15$ system (vide infra). ${ }^{56}$ On the other hand, this mechanism can hardly explain the results for epoxides 33a-33c, in which the regioselectivity observed is opposite to that expected for an acyclic intermediate. In the case of pyridyl epoxides 33a and 33b (bearing electron withdrawing groups), only the alcohols of type $\mathbf{3 6}$ ( $\alpha$-opening) were isolated (entries 1 and 2); on the other hand, in presence of $\mathrm{OCH}_{3}$ substituent on one phenyl ring, only regioisomer 35 ( $\beta$-opening) was obtained (entry 3 ). These results indicate more likely the activated epoxide as reactive species, in which the electrophilicity of the two oxiranyl carbons rules the reactivity.

Beyond mechanistic considerations, the method appears of synthetic value for the direct access to substituted alcohols of type 35a and 36a (Figure 8), which can be envisaged as ligands in asymmetric synthesis. 


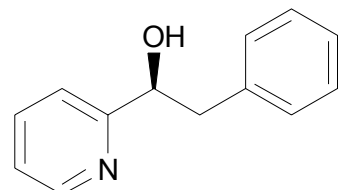

$35 a$

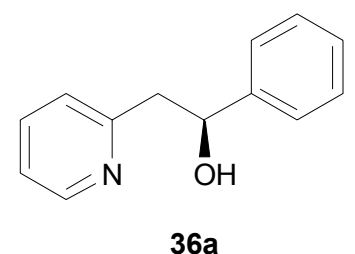

$36 a$

\section{Figure 8}

The application of the described methodologies led to the preparation of new anilinecontaining aminoalcohols in enantiopure form, as intermediates for the synthesis of chiral ligands and bases.

$(R, R)$-2-Nitrophenyl epoxide 38 was therefore prepared in $67 \%$ isolated yield and $>99 \%$ ee (determined by HPLC) from the pure $\left(R, R, R, S_{S}\right)-(-)$-sulfonium salt 26, commercial 2nitrobenzaldehyde and the phosphazene base $\mathrm{EtP}_{2}$ (scheme 12). Since no examples were described on reduction of nitroaryl group in presence of epoxide, different reagents were tested, such as $\mathrm{LiAlH}_{4}$, or milder systems as $\mathrm{FeCl}_{3} \cdot 6 \mathrm{H}_{2} \mathrm{O} / \mathrm{H}_{2} \mathrm{NNMe}_{2}, \mathrm{H}_{2} / \mathrm{NiB}_{2}, \mathrm{Sm} / \mathrm{I}_{2}$, without success. Catalytic hydrogenation over $\mathrm{Pd} / \mathrm{C}$ led quantitatively to $86 / 13$ mixture of the aminoalcohols $(S)$ 39 and $(S)-40$, obtained in $80 \%$ isolated yield. Alternatively, treatment with $\mathrm{NaBH}_{4}$ and catalytic amount of $\mathrm{Pd} / \mathrm{C}$ provided amino alcohol $(S)-\mathbf{4 0}$, as the only isolable product, in good yield. ${ }^{57}$ Both anilino alcohols showed the same ee of the parent epoxide.

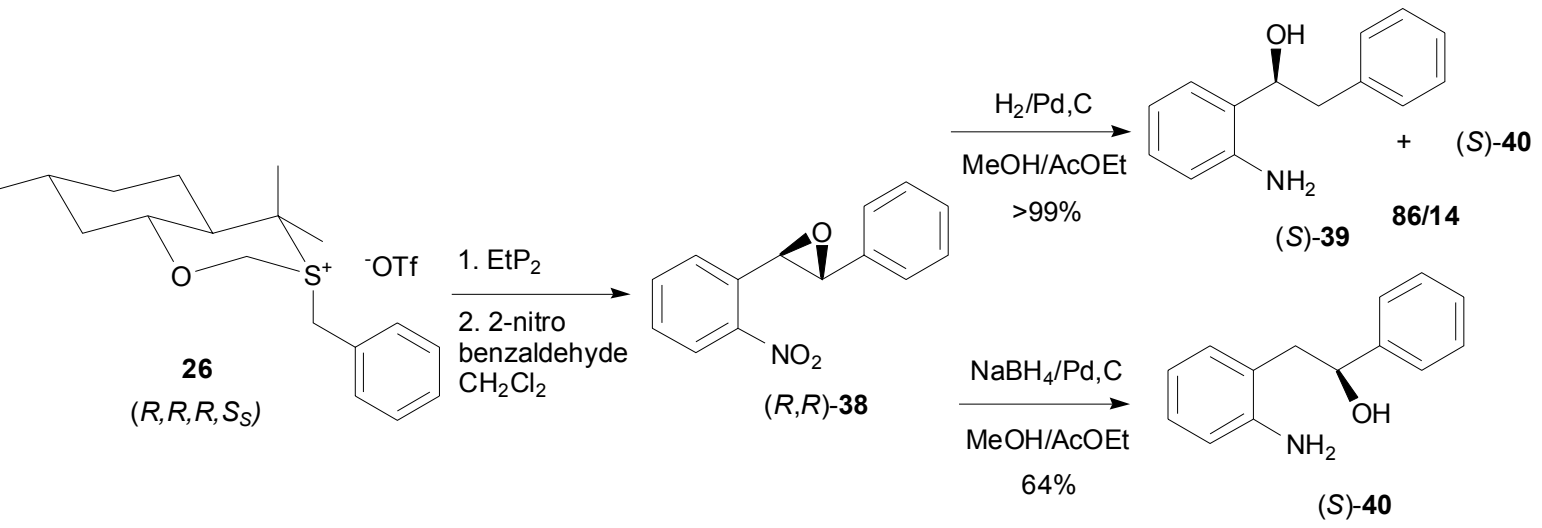

\section{Scheme 12}

Elaboration of amino alcohols allowed the selective alkylation of either amino or hydroxyl group, and all the possible alkylated derivatives were obtained, alternatively (scheme 13).

$\mathrm{N}, \mathrm{N}$-dimethylated anilino alcohols were directly obtained in good yield by $\mathrm{LiH} / \mathrm{CH}_{3} \mathrm{I}$ system (route A). These compounds were tested as chiral ligands in the asymmetric alkylation of benzaldehyde with $\mathrm{Et}_{2} \mathrm{Zn}$, and only the product from regioisomer of type $\mathbf{4 0}$ gave some induction ( $40 \%$ ee of the corresponding 1-phenylpropanol). Using anhydrous $\mathrm{Mg}\left(\mathrm{ClO}_{4}\right)_{2} /(\mathrm{Boc})_{2} \mathrm{O}$ system ${ }^{58}$ on $\mathrm{N}$-Boc protected anilino alcohols, the corresponding $O$-tert-butyl derivatives were obtained, 
which were subsequently reduced by $\mathrm{LiAlH}_{4}{ }^{59}$ to afford the $\mathrm{N}$-monomethyl- $O$-alkylated derivatives, precursors of new strong chiral bases (route B). Selective monomethylated anilino alcohols were obtained by introduction of Boc group on nitrogen followed by reduction with $\mathrm{LiAlH}_{4}$ (route C). Finally, the synthetically challenging $O$-alkylated anilino alcohols were obtained from the $N$-Boc derivatives by the use of wet $^{60} \mathrm{Mg}\left(\mathrm{ClO}_{4}\right)_{2} /(\mathrm{Boc})_{2} \mathrm{O}$ system, which effected tert-butylation of hydroxyl group together with hydrolysis of Boc group (route $\mathbf{D}$ ).

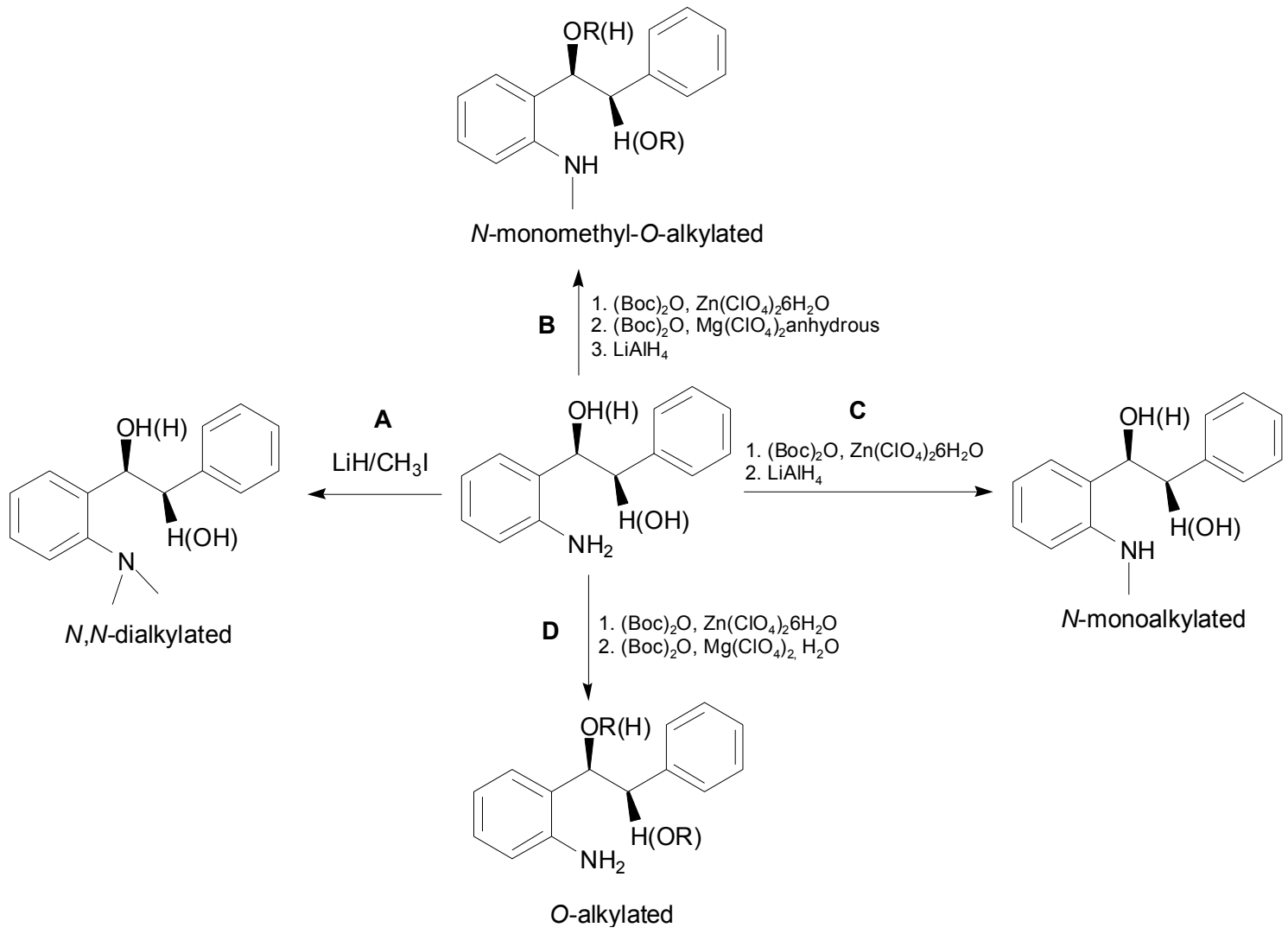

\section{Scheme 13}

\subsection{Nucleophilic ring opening by metal halides}

Vicinal halo alcohols have attracted the interest of organic chemists for their usefulness as versatile building blocks. ${ }^{61}$ They are also substrates for a particular class of enzymes, halohydrin dehalogenases, ${ }^{62}$ that are of interest both to organic synthesis ${ }^{63}$ (e.g., chiral resolution of racemic compounds ${ }^{64}$ ) and bioremediation of the environment (e.g., removal of pollutants from soil, ground-water or waste-water ${ }^{62,65}$ ). Although various synthetic procedures have been reported, most of them have some limitations, in terms of either harsh reaction conditions or low regioselectivity in the opening of unsymmetrical epoxides. ${ }^{66}$ In more recent years, new and milder procedures have been proposed, with the use of silyl halides in the presence of different promoters, ${ }^{67}$ elemental halogen with various catalysts, ${ }^{68}$ borane halogenides ${ }^{69}$ and metal halides with Lewis ${ }^{70}$ or Brønsted ${ }^{71}$ acid systems. The use of ionic liquids has broadened the application 
of such procedures. ${ }^{72}$ Among all these methods, very few are suitable for regioselective openings of nonsymmetrical 2,3-disubstituted oxiranes and, in such cases, regio- and stereoselective openings are usually performed on substrates bearing chelating atoms or groups. ${ }^{73}$

2,3-Diaryloxiranes appeared very challenging for ring opening, due to their low reactivity without acid promoters and the possible competitive rearrangements in such conditions. ${ }^{74}$

In search of efficient conditions for the success of nucleophilic opening of the oxirane ring, different metal halide systems were attempted to the opening of trans-stilbene oxide 41. In particular, the attention was turned to the use of a metal bromide/Amberlyst 15 system $^{75}$ and to the $\mathrm{MgBr}_{2}$ reagent, already successfully employed in the opening of epoxy- and aziridinoalcohols and derivatives. ${ }^{76}$ The results in Table 3 show a general high chemical yield in the obtaining of the corresponding bromohydrines, with different levels of diastereoselectivity, depending on reagents and reaction conditions. ${ }^{77}$ Only in the case of $\mathrm{MgBr}_{2}$, the reaction can be performed in absence of the acidic resin Amberlyst 15, and the expected anti diastereoisomer 42 was obtained in good yield. On the other hand, using alternatively, $\mathrm{MgBr}_{2}, \mathrm{NaBr}$ or $\mathrm{KBr}$ with Amberlyst 15, high syn/anti ratio was always observed and the syn bromohydrin $\mathbf{4 3}$ was obtained in good yield.

Table 3. Opening of trans stilbene oxide with metal halides

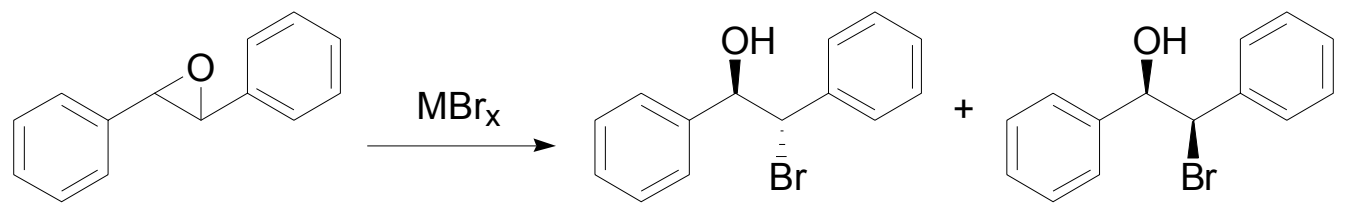
41 trans
42, anti
43, syn

\begin{tabular}{|c|c|c|c|c|c|c|}
\hline \multirow{2}{*}{ Entry $^{\mathrm{a}}$} & \multirow{2}{*}{ Bromides } & \multirow{2}{*}{ React. Cond. } & \multirow{2}{*}{$\begin{array}{c}\text { Conv. }^{a} \\
(\%)\end{array}$} & \multirow{2}{*}{$\begin{array}{l}\text { Yield }^{\mathrm{b}} \\
(\%)\end{array}$} & \multicolumn{2}{|c|}{ Diaster. Ratio $^{a}$} \\
\hline & & & & & 42 & 43 \\
\hline 1 & $\mathrm{MgBr}_{2} \cdot \mathrm{Et}_{2} \mathrm{O}$ & $\mathrm{Et}_{2} \mathrm{O}, 0^{\circ} \mathrm{C}, 4 \mathrm{~h}$ & 95 & 90 & 80 & 20 \\
\hline 2 & $\mathrm{MgBr}_{2} \cdot \mathrm{Et}_{2} \mathrm{O} / \mathrm{Amb} .15$ & $\begin{array}{c}\mathrm{CH}_{3} \mathrm{CN}, 0^{\circ} \mathrm{C}, \\
2 \mathrm{~h}\end{array}$ & 95 & 90 & 10 & 90 \\
\hline 3 & $\mathrm{NaBr} / \mathrm{Amb} .15$ & $\begin{array}{l}\text { Acetone, } \\
-30^{\circ} \mathrm{C}, 12 \mathrm{~h}\end{array}$ & 90 & 60 & 10 & 90 \\
\hline 4 & $\mathrm{NaBr} / \mathrm{Amb} .15$ & $\begin{array}{c}\mathrm{CH}_{3} \mathrm{CN} \\
-30^{\circ} \mathrm{C}-0^{\circ} \mathrm{C}, 6 \mathrm{~h}\end{array}$ & 95 & 80 & 10 & 90 \\
\hline 5 & $\mathrm{KBr} / \mathrm{Amb} .15$ & $\begin{array}{c}\mathrm{CH}_{3} \mathrm{CN} \\
\text { r.t. } 3 \mathrm{~h}\end{array}$ & 95 & 90 & 25 & 75 \\
\hline
\end{tabular}

${ }^{\mathrm{a} C a l c u l a t e d}$ by ${ }^{1} \mathrm{H}$ NMR analysis of the crude mixture. ${ }^{\mathrm{b}}$ Isolated.

Using the results of this investigation, a new stereodivergent synthesis of optically pure anti and syn 2-amino-1,2-diphenylethanols was achieved (scheme 14). After a straightforward 
obtainment of the two diastereoisomers $(1 R, 2 S)-\mathbf{4 2}$ and $(1 R, 2 R)-\mathbf{4 3}$ from the epoxide $(R, R)-\mathbf{4 1}$, they were transformed with sodium azide, via direct $\mathrm{S}_{\mathrm{N}} 2$-type replacement of the bromine, to the corresponding azidoalcohols $\mathbf{4 4}$ and $\mathbf{4 5}$ in high yield and without traces of racemization. Standard catalytic hydrogenation finally afforded enantiopure $\mathbf{4 6}$ and $\mathbf{4 7 .}$
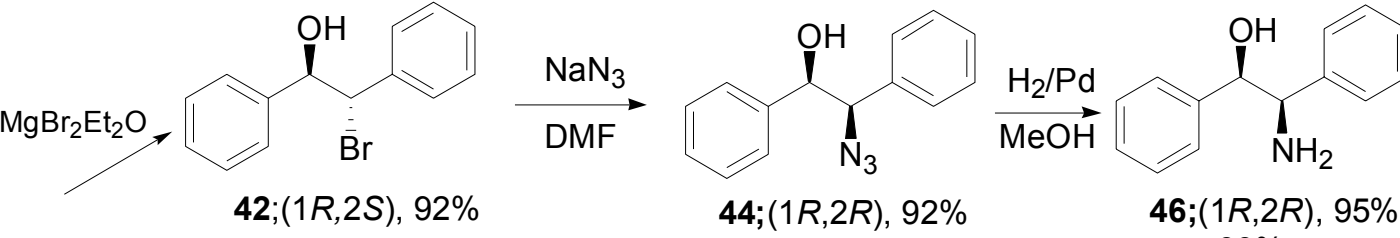

$41,(R, R)$

46;(1R,2R), 95\%

$99 \%$ ee

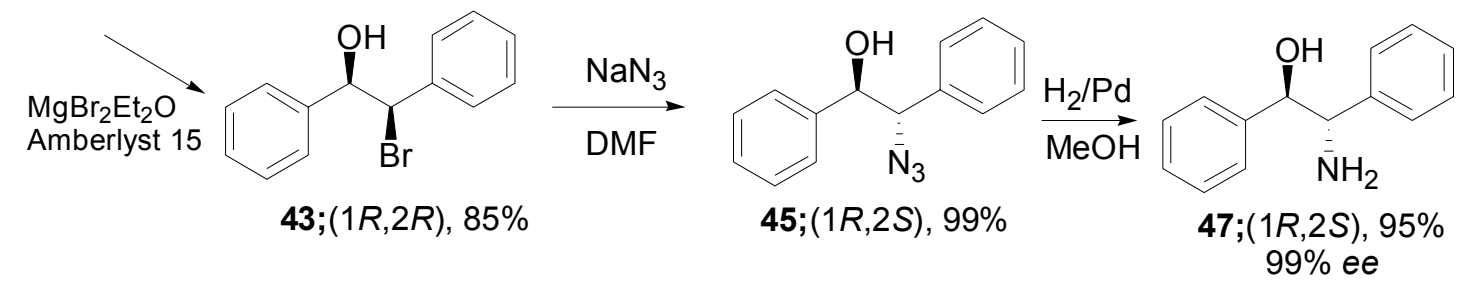

Scheme 14. Stereodivergent synthesis of 2-amino-1,2-diphenylethanols.

Subsequent studies on nonsymmetrical substituted 2,3-diaryloxiranes showed the efficiency of these procedures in terms of both regio- and stereoselectivity of the ring opening (Table 4). The behaviour of trans 2-pyridyl- and 2-fluorophenyl epoxides 33a and $\mathbf{4 8}$ in presence of either $\mathrm{MgBr}_{2}$ or $\mathrm{NaBr} / \mathrm{Amberlyst} 15$ system was studied. In the case of 33a only the regioisomer 49 was obtained in all reaction conditions (with either $\mathrm{MgBr}_{2}$ or $\mathrm{NaBr} / \mathrm{Amb}$. 15), in diastereoisomeric ratios ranging from $4 / 1$ to $>98 / 2$ in favour of the anti stereoisomer 49I. 2fluorophenyl epoxide 48 and $\mathrm{MgBr}_{2}$ provided only the two anti isomers $50 \mathrm{I}$ and $\mathbf{5 1 I}$ (of the four possible isomers) in the ratio $\sim 4: 1$ in favor of regioisomer 50I. On the other hand, $\mathrm{NaBr} / \mathrm{Amb}$. 15 gave, in quantitative yield, a mixture of all four isomers, with the syn bromohydrin $\mathbf{5 0 I I}$ as the major compound. ${ }^{78}$ 


\section{Table 4}

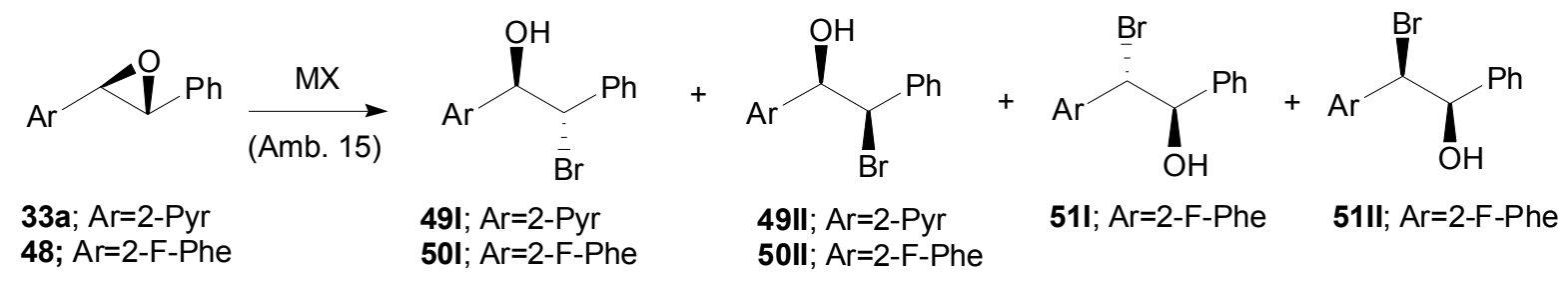

\begin{tabular}{|c|c|c|c|c|c|c|c|c|}
\hline \multirow[b]{2}{*}{ Entry $^{\mathrm{a}}$} & \multirow[b]{2}{*}{ Epox. } & \multirow[b]{2}{*}{ Bromide } & \multirow[b]{2}{*}{ React. Cond. } & \multirow{2}{*}{$\begin{array}{c}\text { Conv. }{ }^{a} \\
(\%)\end{array}$} & \multicolumn{4}{|c|}{ Product ratios $^{\mathrm{a}}$} \\
\hline & & & & & $\begin{array}{c}49-50 \\
\text { I }\end{array}$ & $\begin{array}{c}49-50 \\
\text { II }\end{array}$ & $\begin{array}{c}51 \\
\text { I }\end{array}$ & $\begin{array}{l}51 \\
\text { II }\end{array}$ \\
\hline 1 & $33 \mathbf{a}$ & $\mathrm{MgBr}_{2} \cdot 2 \mathrm{Et}_{2} \mathrm{O}^{\mathrm{b}}$ & $\mathrm{Et}_{2} \mathrm{O}, 0^{\circ} \mathrm{C}, 1 \mathrm{~h}$ & Quant. & $>98^{\mathrm{c}}$ & - & - & - \\
\hline 2 & $33 \mathbf{a}$ & $\mathrm{MgBr}_{2} \cdot 1 \mathrm{Et}_{2} \mathrm{O}^{\mathrm{d}}$ & $\mathrm{Et}_{2} \mathrm{O}$, r.t., $18 \mathrm{~h}$ & 90 & 92 & 8 & - & - \\
\hline 3 & $33 \mathbf{a}$ & $\mathrm{NaBr} / \mathrm{Amb} .15$ & $\begin{array}{c}\text { Acetone, } \\
\text { r.t., } 48 \mathrm{~h}\end{array}$ & 87 & 80 & 20 & - & - \\
\hline 4 & 48 & $\mathrm{MgBr}_{2} \cdot 2 \mathrm{Et}_{2} \mathrm{O}^{\mathrm{b}}$ & $\mathrm{Et}_{2} \mathrm{O}$, r.t., $18 \mathrm{~h}$ & 98 & 84 & - & 16 & - \\
\hline 5 & 48 & $\mathrm{MgBr}_{2} \cdot 1 \mathrm{Et}_{2} \mathrm{O}^{\mathrm{d}}$ & $\mathrm{Et}_{2} \mathrm{O}, 0^{\circ} \mathrm{C}, 3 \mathrm{~h}$ & 83 & 82 & - & 18 & - \\
\hline 6 & 48 & $\mathrm{NaBr} / \mathrm{Amb} .15$ & $\begin{array}{l}\text { Acetone, } \\
\text { r.t., } 12 \mathrm{~h}\end{array}$ & Quant. & 13 & 62 & 10 & 15 \\
\hline
\end{tabular}

${ }^{\mathrm{a}}$ Determined by ${ }^{1} \mathrm{H}$ NMR spectroscopy of the crude productof the reaction. ${ }^{\mathrm{b}} 3 \mathrm{M}$ solution in $\mathrm{Et}_{2} \mathrm{O}$, freshly prepared from $\mathrm{Mg}$ and 1,2-dibromoethane in diethyl ether ${ }^{79}{ }^{\mathrm{c}}$ Isolated yield. ${ }^{\mathrm{d}}$ Commercial.

The difference found in regioselectivity of the reactions with $\mathrm{MgBr}_{2}$ has been explained by the assistance of neighbouring group, which is weaker in the case of fluorine (epoxide 48) although the bite angle ${ }^{80}$ is more favourable in the case of epoxide 48 (six-membered ring) than in epoxide 33a (five-membered ring) in presence of small cations such as magnesium (Figure 9). The complexing ability of nitrogen is strong enough to overcome the effect of the bite angle and direct the approach of the reagent, resulting in a complete regioselectivity in the case of epoxide $33 a$.

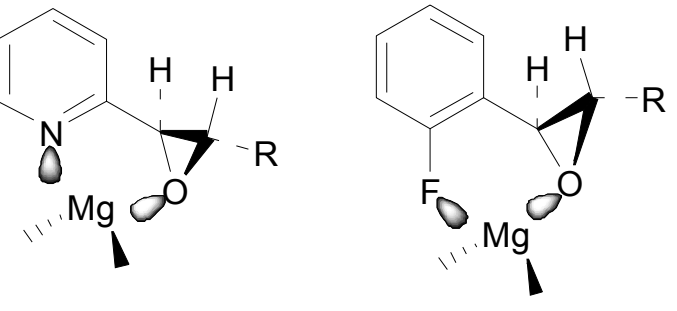

Figure 9. 5- and 6-membered chelates 
The lower diastereoselectivity obtained with $\mathrm{NaBr} / \mathrm{Amb}$. 15 protocol (with unexpected 50II as the major product in the case of epoxide 48), suggested a different mechanism for the epoxide ring opening, through the formation of an acyclic intermediate.

All these results prompted us to study, more deeply, both the influence of reaction conditions on the stereoselectivity in the opening of the model $(E)$-stilbene oxide and on the regioselectivity in the opening of nonsymmetrical substituted 2,3-diaryloxiranes. ${ }^{81}$ Thus, a systematic study has been conducted, analyzing the influence of different parameters (substrate/bromide ratio, substrate/Amberlyst 15 ratio, temperature, reagents concentration) on the stereoselectivity in the opening of $(E)$-stilbene oxide 41 with the LiBr/Amberlyst 15 system (Table 5).

Table 5. LiBr/Amb 15 promoted ring opening of trans-stilbene oxide in different reaction conditions

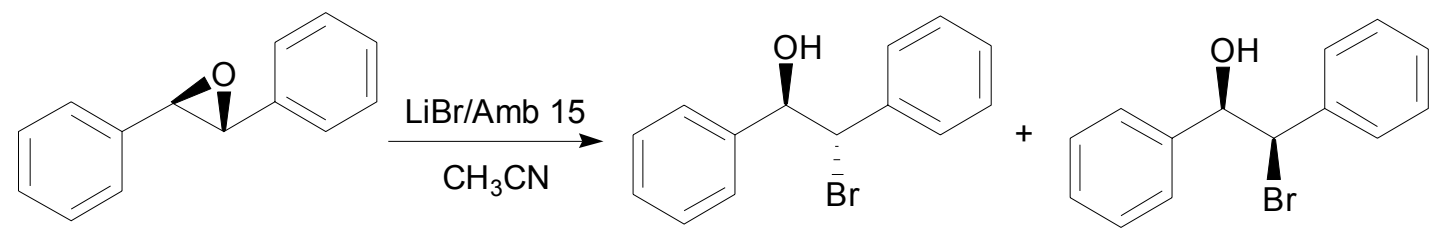

41; (E)-stilbene oxide

42; anti

43; syn

\begin{tabular}{cccccccc}
\hline Entry & $\begin{array}{c}\text { LiBr/ } \\
\text { substr. }\end{array}$ & $\begin{array}{c}\text { Amb/substr. } \\
\text { mg/mmol }\end{array}$ & $\mathrm{T}$ & Time & ${\text { Conv. }(\%)^{\mathrm{a}}}^{\text {Y Yield }(\%)^{\mathrm{b}}}$ & Syn/anti $^{\mathrm{a}}$ \\
\hline 1 & $2 / 1$ & 440 & r.t. & $1 \mathrm{~h}$. & 100 & 95 & $88 / 12$ \\
2 & $2 / 1$ & 220 & r.t. & $6 \mathrm{~h}$ & 81 & 80 & $83 / 17$ \\
3 & $4 / 1$ & 440 & r.t. & $50 \mathrm{~min}$ & 100 & 95 & $75 / 25$ \\
4 & $4 / 1$ & 220 & $-15^{\circ} \mathrm{C}$ & $6 \mathrm{~h}$ & 80 & 80 & $47 / 53$ \\
5 & $4 / 1$ & 220 & $-25^{\circ} \mathrm{C}$ & $18 \mathrm{~h}$ & 70 & 70 & $50 / 50$ \\
6 & $4 / 1$ & 440 & $-30^{\circ} \mathrm{C}$ & $2 \mathrm{~h} 30 \mathrm{~min}$ & 100 & 95 & $30 / 70$ \\
7 & $4 / 1$ & 0 & r.t. & $4 \mathrm{~h}$. & & no reaction & \\
\hline
\end{tabular}

${ }^{\mathrm{a}}$ Calculated by ${ }^{1} \mathrm{H}$ NMR analysis of the crude mixture. ${ }^{\mathrm{b}}$ Isolated.

Among the different parameters, the reaction temperature seems dramatically effect the stereoselectivity of the ring opening. At room temperature, the bromohydrins were obtained in high yield, with a syn/anti ratio ranging between 75/25 and 88/12 (entries 1-3). With lower reaction temperature, the amount of anti-bromohydrin 42 increased, until becoming the major reaction product below $-25^{\circ} \mathrm{C}$. Basing on these results, the formation of an acyclic cationic-type intermediate, which competes with a classical $\mathrm{S}_{\mathrm{N}} 2$ opening has been postulated. The syn bromohydrin 43 resulted more favorable at room temperature. By lowering the temperature the formation of the acyclic intermediate becomes less probable and an $\mathrm{S}_{\mathrm{N}} 2$ opening with inversion of configuration becomes competitive with the decreasing of the syn/anti ratio. 
The study of the behaviour of nonsymmetrical para-substituted 2,3-diaryloxiranes with $\mathrm{LiBr} /$ Amberlyst 15 system also allowed to rationalize of the substituent effects on the regioselectivity of the ring opening. ${ }^{81}$ Different $p$-substituted (E)-2,3-diaryloxiranes were prepared in good yield by the reaction of benzyliden sulfurylide with the appropriate aldehyde and then allowed to react with $\mathrm{LiBr} / \mathrm{Amberlyst} 15$ at room temperature (Table 6).

Table 6. $\mathrm{LiBr} / \mathrm{Amb} 15$ promoted ring opening of nonsymmetrical 2,3-substituted oxiranes, at room temperature (except entry 4$)$

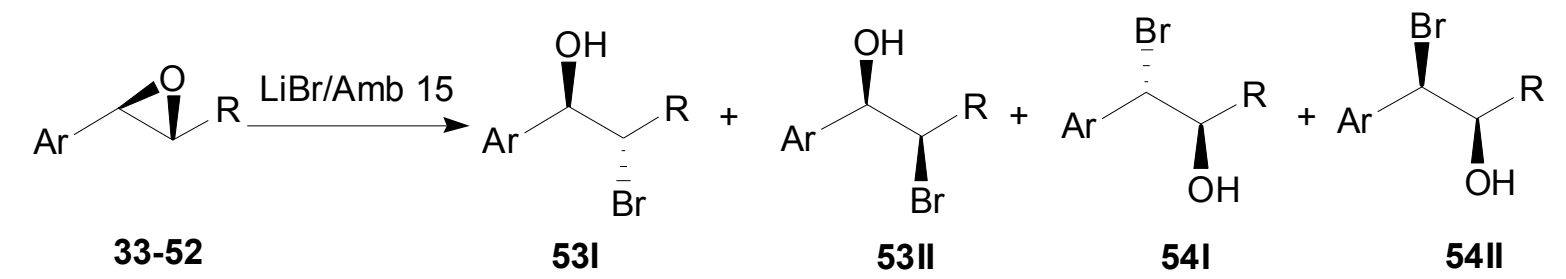

\begin{tabular}{ccccccccc}
\hline \multirow{2}{*}{ Entry $^{\mathrm{a}}$} & \multirow{2}{*}{} & Epoxide & $\mathrm{R}$ & \multirow{2}{*}{$\mathrm{Ar}$} & Time & \multicolumn{2}{c}{$\beta$-opening } & \multicolumn{2}{c}{$\alpha$-opening } \\
\cline { 6 - 9 } & & & $\mathbf{5 3 I}^{\mathrm{b}}$ & $\mathbf{5 3 I I}^{\mathrm{b}}$ & $\mathbf{5 4 I}^{\mathrm{b}}$ & $\mathbf{5 4 I I}^{\mathrm{b}}$ \\
\hline 1 & $\mathbf{5 2}$ & $\mathrm{Ph}$ & $p-\mathrm{NO}_{2} \mathrm{Ph}$ & $1 \mathrm{~h}$ & 69 & 31 & - & - \\
2 & $\mathbf{3 3 e}$ & $\mathrm{Ph}$ & $p-\mathrm{CF}_{3} \mathrm{Ph}$ & $45 \mathrm{~min}$ & 57 & 38 & 5 & - \\
3 & $\mathbf{3 3 f}$ & $\mathrm{Ph}$ & $p-\mathrm{FPh}$ & $40 \mathrm{~min}$ & $22^{\mathrm{c}}$ & $18^{\mathrm{c}}$ & $22^{\mathrm{c}}$ & $38^{\mathrm{c}}$ \\
4 & $\mathbf{3 3 c}$ & $\mathrm{Ph}$ & $p-\mathrm{OCH} \mathrm{H}_{3} \mathrm{Ph}$ & $2 \mathrm{~h}\left(-30^{\circ} \mathrm{C}\right)$ & - & - & $95(\text { d.r. } 3 / 2)^{\mathrm{d}}$ \\
5 & $\mathbf{3 3 g}$ & $\mathrm{CH}_{3}$ & $\mathrm{Ph}$ & $1 \mathrm{~h}$ & - & - & $81^{\mathrm{c}}$ & $19^{\mathrm{c}}$ \\
\hline
\end{tabular}

${ }^{\mathrm{a}}$ All the reactions were performed at r.t., with $\mathrm{LiBr} / \mathrm{substrate}=4 / 1, \mathrm{Amb} 15 /$ substrate $=440$ $\mathrm{mg} / \mathrm{mmol}$. The conversions were higher than $99 \%$ and were determined by ${ }^{1} \mathrm{H}$ NMR spectroscopy of the crude product. ${ }^{b}$ Determined by ${ }^{1} \mathrm{H}$ NMR spectroscopy of the crude product. ${ }^{\mathrm{c}}$ Determined by GC/MS analysis of the crude together with GC/MS and ${ }^{1} \mathrm{H}$ NMR analysis of the alkaline ring closure of the bromohydrins mixture. ${ }^{\mathrm{d}}$ The bromohydrins were characterized as acetates.

The results showed a dramatic effect of substituents electronic properties on the regioselectivity. In the oxiranes with one phenyl ring bearing a strong $\mathrm{EWG}\left(\mathrm{NO}_{2}, \mathrm{CF}_{3}\right.$ : entries 1 and 2), only the regioisomer $\mathbf{5 3}$ was detected in the reaction mixture, with the exclusive attack of the nucleophile is on the $\beta$-carbon with respect to the substituted phenyl ring. In the presence of a strong ERG $\left(\mathrm{OCH}_{3}\right)$ on the phenyl ring, the regioisomer 54 ( $\alpha$-opening) was the only observed reaction product. In the case of trans- $\beta$-methyl stirene epoxide (entry 5), the reaction was completely regioselective toward $\mathbf{5 4}$, via an attack of the bromide on the most electrophilic benzyl carbon.

The hypothesis of the formation of an acyclic cationic-type intermediate as the key step of the reaction was confirmed by theoretical calculation, run on the protonated epoxides $\mathbf{5 5}$ and $\mathbf{5 6}$ (Figure 10), which were considered as model structures for the reactive intermediate. 


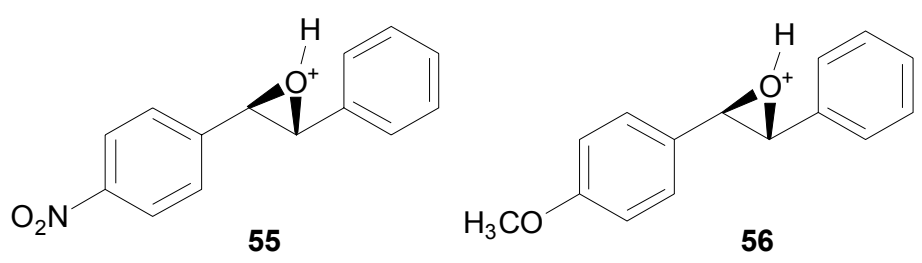

Figure 10

In fact these structures invariably converge to acyclic cationic structures, if submitted to semiempirical calculation at the PM3 level. Once carried out a conformational search on the two couples of opened cationic structures by this level of calculation, each conformer was then submitted to $a b$ initio calculation at the DFT/B3LYP/6-31 $\mathrm{G}^{*}$ level. Comparing the predicted free energies of the two opened $p-\mathrm{NO}_{2}$ cationic structures $\mathbf{5 2} \mathbf{a}\left(\mathrm{H}^{+}\right) \mathbf{A}$ and $\mathbf{5 2} \mathbf{a}\left(\mathrm{H}^{+}\right) \mathbf{B}$, which would give products $\mathbf{5 3}$ and $\mathbf{5 4}$ respectively, a difference in stability of $4.1 \mathrm{kcal} / \mathrm{mol}$ in favor of structure 52a $\left(\mathrm{H}^{+}\right) \mathbf{A}$ was calculated, which accounts for the complete regioselectivity of the reaction (Figure 11). The same comparison between the free energies of $p-\mathrm{OCH}_{3}$ cationic structures $33 \mathbf{c}\left(\mathrm{H}^{+}\right) \mathbf{A}$ and $33 \mathbf{c}\left(\mathrm{H}^{+}\right) \mathbf{B}$ (Figure 12) provided a difference in stability of $7.6 \mathrm{kcal} / \mathrm{mol}$ in favor of $\mathbf{3 3} \mathbf{c}\left(\mathrm{H}^{+}\right) \mathbf{B}$, in accordance with the opposite regioselectivity observed for epoxide $\mathbf{3 3} \mathbf{c}$.

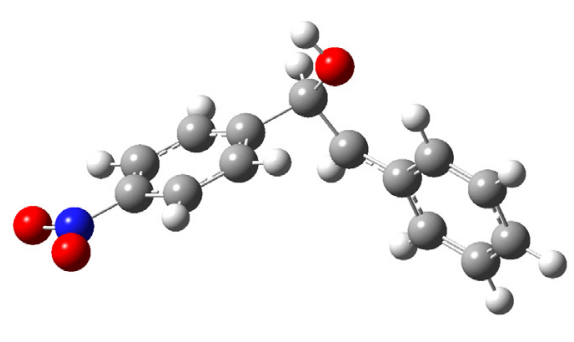

52a $\left(\mathrm{H}^{+}\right) \mathbf{A}$ more stable

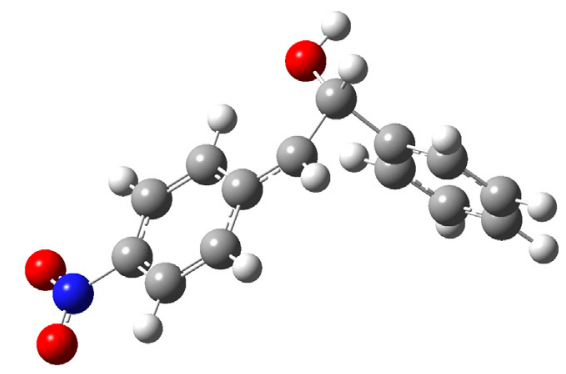

52a $\left(\mathrm{H}^{+}\right) \mathbf{B}$ less stable

Figure 11. Minimized structures for $\mathbf{5 2} \mathbf{a}\left(\mathrm{H}^{+}\right) \mathbf{A}$ and $\mathbf{5 2 a}\left(\mathrm{H}^{+}\right) \mathbf{B}$

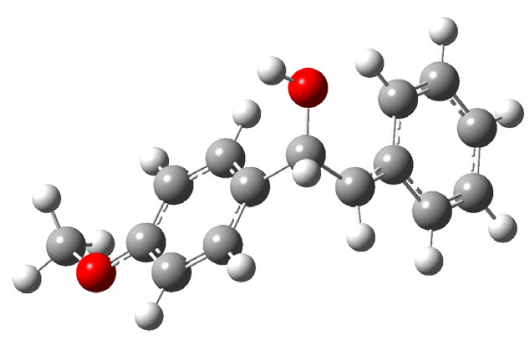

$33 \mathrm{c}\left(\mathbf{H}^{+}\right) \mathrm{A}$ less stable

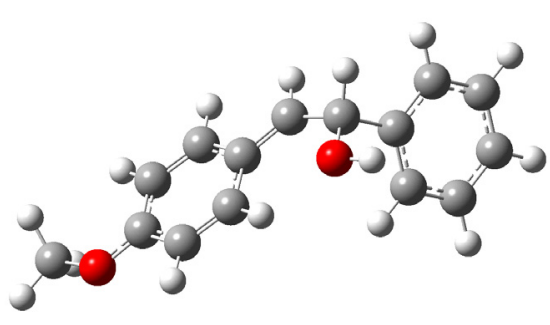

33c $\left(\mathrm{H}^{+}\right)$B more stable

Figure 12. Minimized structures for $\mathbf{3 3} \mathbf{c}\left(\mathrm{H}^{+}\right) \mathbf{A}$ and $\mathbf{3 3 c}\left(\mathrm{H}^{+}\right) \mathbf{B}$ 
Useful intermediates of new polydentate ligands were prepared starting from enantiopure ortho substituted 2,3-diaryloxiranes 38 and 33h (Scheme 15). Both the starting epoxides were prepared in good yield using the Solladiè-Cavallo epoxidation methodology. ${ }^{81}$ Both epoxides afforded the corresponding syn-bromohydrins $\mathbf{5 7}$ and 58, respectively, in excellent to quantitative yield, via a regio- and stereoselective opening with retention of configuration at the reactive carbon. Substitution of bromine with azide and final reduction gave the tridentate amino alcohols with no loss of optical purity.

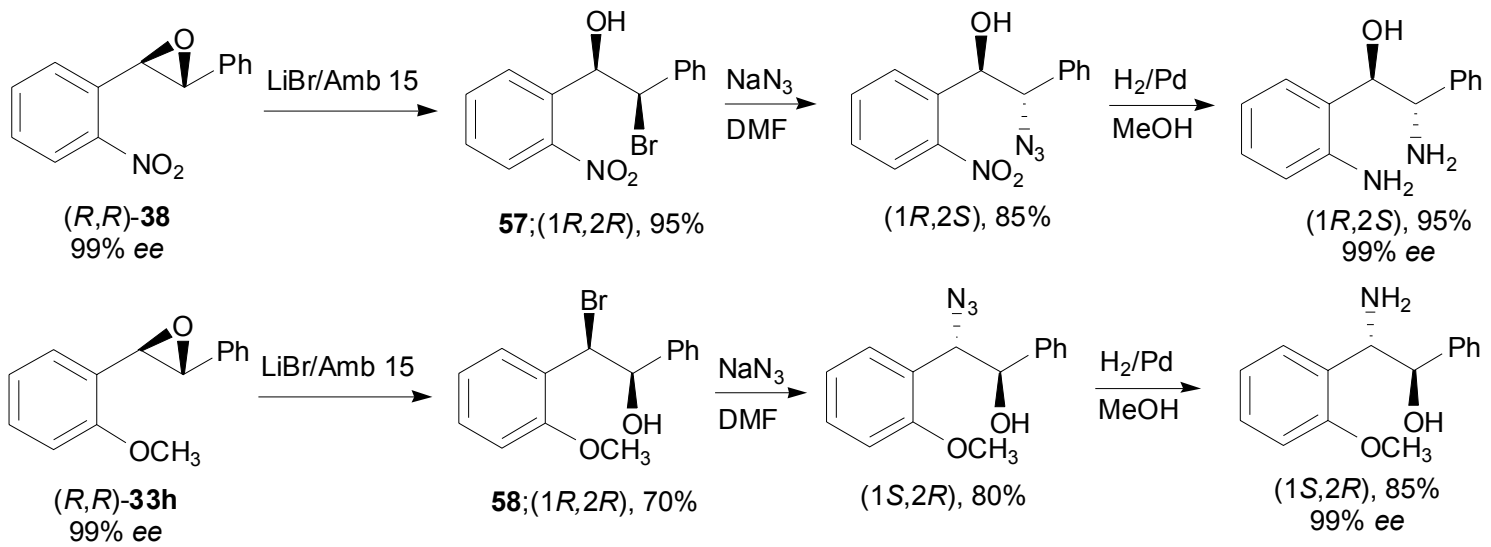

\section{Scheme 15}

\subsection{Ring opening by oxygen nucleophiles}

Ring opening reaction of epoxides by oxygen nucleophiles represents a traditional method for the preparation of 1,2-diol derivatives. ${ }^{82}$ Hydrolysis of epoxides is usually catalyzed by acids and bases. Among the acid catalysts perchloric acid is preferred, since side reaction are minimized. Dimethyl sulfoxide appears a superior solvent for the alkaline hydrolysis of epoxides. In general, the reaction remains difficult, mainly because alcohols, and particularly phenols, behave as poor nucleophilic reagents in substitution process. Strong acidic or basic conditions or metal-catalyzed reactions usually occur in anti-stereoselective fashion ${ }^{83}$ and catalytic asymmetric versions have also been developed. ${ }^{84}$ Vinyl and aryl epoxides are only moderately reactive under classical displacement conditions and they need the presence of transition metal catalysts. ${ }^{85} \mathrm{~A}$ mild rhodium-catalyzed reaction of vinyl epoxides with alcohols has been described occurring with excellent anti -stereo- and 1,2-regioselectivity. ${ }^{86}$ Complementarily, a simple method for the synnucleophilic displacement of aryl and vinyl epoxides with substituted phenols, using aryl borates as activating nucleophiles, has been recently reported. ${ }^{87}$ Electronegatively-substituted iron porphyrin complex has been shown to efficiently catalyze the ring-opening reaction of various epoxides by methanol and water under mild and neutral conditions to give stereospecifically the corresponding mono-ethers 1,2-diols and with moderate regioselectivity. ${ }^{88}$ Substrate-dependent stereoselective ring opening of enantiopure epoxides has been described with the use of nitric 
oxide (and traces of $\mathrm{O}_{2}$ ). Thus, $(R, R)$ trans stilbene oxide has been transformed in high yield in the corresponding syn hydroxy nitrate. ${ }^{89}$

The 2,2-dimethyl-1,3-dioxolane (acetonide) group is a widely used protecting group for vicinal diols. The direct conversion of epoxides to the corresponding acetonides has been described with the use of different Lewis acid catalysts. Various degree of success in terms of yield and selectivity has been shown by anhydrous $\mathrm{SnCl}_{2},{ }^{90} \operatorname{tin}(\mathrm{IV})$ tetraphenylporphyrin perchlorate, ${ }^{91}$ bismuth(III) salts, ${ }^{92}$ titanium complexes, ${ }^{93}\left[\left(\mathrm{C}_{5} \mathrm{Me}_{5}\right)-\operatorname{Ir}\left(\mathrm{NaMe}_{3}\right)\right],{ }^{94} \mathrm{RuCl}_{3},{ }^{95}$ $\mathrm{CH}_{3} \mathrm{ReO}_{3},{ }^{96} \mathrm{Cu}(\mathrm{OTf})_{2},{ }^{97} \mathrm{Er}(\mathrm{OTf})_{3},{ }^{98} \mathrm{BF}_{3} \cdot \mathrm{Et}_{2} \mathrm{O},{ }^{99} \mathrm{LiBF}_{4},{ }^{100}$ and heteropolyacids. ${ }^{101}$

The transformation of epoxides into the corresponding acetonides by these reagents usually occurs through a $\mathrm{S}_{\mathrm{N}} 2$ mechanism, with inversion of configuration at the oxiranyl carbon approached by acetone. Thus, trans-symmetrical 2,3-substituted oxiranes lead invariably to meso-acetonides, loosing any possible chiral information of the substrate.

The direct conversion of epoxides into 2,2-dimethyl-1,3-dioxolanes (acetonides) by acetone in the presence of the acid resin Amberlyst 15 has overcome this limitation. ${ }^{102}$ In the case of trans-2,3-disubstituted oxiranes such as trans-stilbene oxide 41 and trans- $\beta$-methylstirene oxide $\mathbf{3 3 h}$, a high stereoselectivity towards trans-acetonides, with a neat retention of configuration at the oxiranyl carbon atom, has been reported ${ }^{102}$ (Scheme 16).

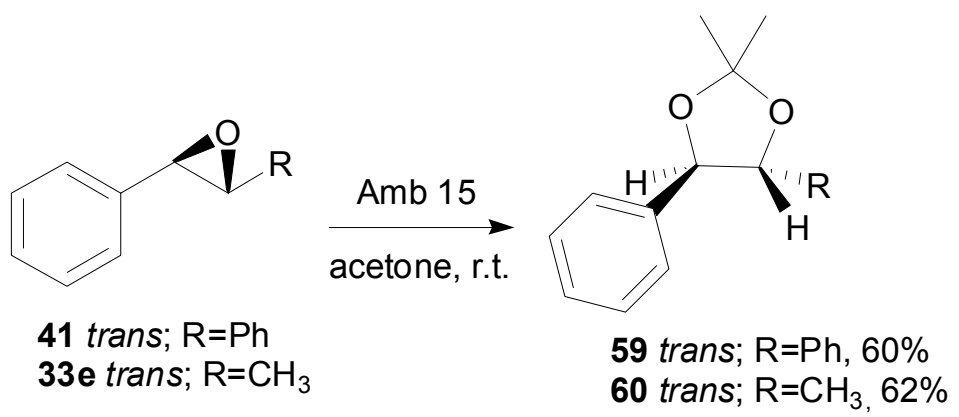

\section{Scheme 16}

The study on trans-stilbene oxide has shown, as previously noted in the reaction with lithium bromide, a strong effect of temperature on the reaction stereoselectivity, with the highest trans/cis ratio of $3 / 2$ obtained at room temperature. Upon lowering the temperature, the formation of the cis isomer, by a classical $\mathrm{S}_{\mathrm{N}} 2$ ring opening with inversion of configuration, increases, and cis isomer becomes the major reaction product below $-10^{\circ} \mathrm{C}$.

The procedure has been successfully extended to optically pure and non symmetrically substituted epoxides, such as $\mathbf{3 3 h}, \mathbf{3 8}$ and 41, which has afforded the corresponding enantiopure trans acetonides 61-63 in good yield (Scheme 17). 


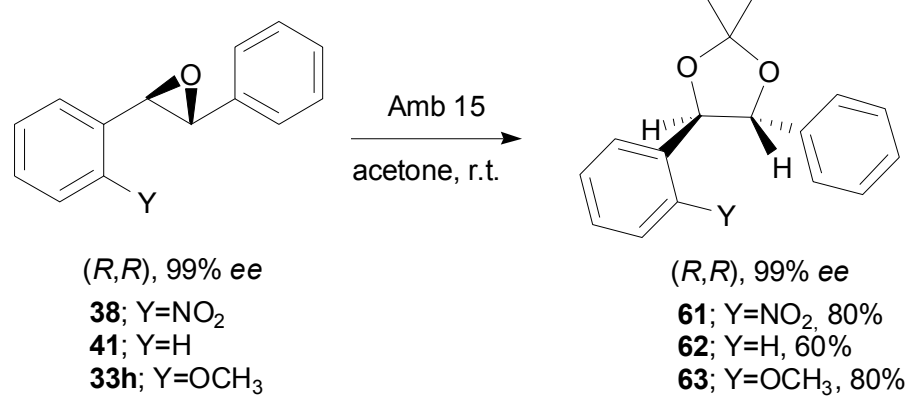

\section{Scheme 17}

Elaboration of acetonide $\mathbf{6 1}$ has allowed the preparation of the aminodiol $\mathbf{6 5}$, which can be used as tridentate ligand in asymmetric synthesis (Scheme 18).

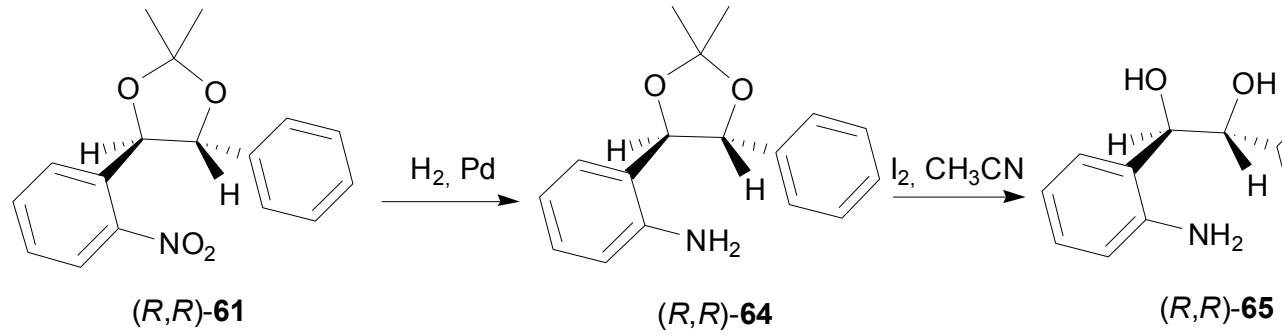

\section{Scheme 18}

\section{Acknowledgements}

We thank MIUR (Ministry of University and Research-Rome) (Project FIRB RBNE017F8N and PRIN 2005), the University of Basilicata, University Louis Pasteur and CNRS for financial support and ERASMUS grants.

\section{References and Notes}

1. For asymmetric approaches to (+)-disparlure see: (a) Marczak, S.; Masnyk, M.; Wicha, J. Liebigs Ann. Chem. 1990, 345. (b) Keinan, E.; Sinha, S. C.; Sinha-Bagchi, A.; Wang, Z.-M.; Zhang, X.-L.; Sharpless, K. B. Tetrahedron Lett. 1992, 33, 6411. For epothilone syntheses see: (c) Nicolaou, K. C.; Roschangar, F.; Vourloumis, D. Angew. Chem., Int. Ed. 1998, 37, 2014. (d) Hindupur, R. M.; Panicker, B.; Valluri, M.; Avery, M. A. Tetrahedron Lett. 2001, 42,7341 .

2. Kolb, H. C.; Finn, M. G.; Sharpless, K. B. Angew. Chem. Int. Ed. 2001, 40, 2004. 
3. (a) Seebach, D.; Aebi, J. D.; Gander-Coquoz, M.; Naef, R. Helv. Chim. Acta 1987, 70, 1194. (b) Satoh, T. Chem. Rev. 1996, 96, 3303. (c) Satoh, T.; Kobayashi, S.; Nakanishi, S.; Horiguchi, K.; Irisa, S. Tetrahedron 1999, 55, 2515. (d) Mori, Y.; Yaegashi, K.; Furukawa, H. J. Am. Chem. Soc. 1997, 119, 4557.

4. Jacobsen, E. N.; Wu, M.H In: Comprehensive Asymmetric Synthesis, Jacobsen, E. N.; A. Pfaltz, A.; Yamamoto, H., Eds., Springer: Berlin, 1999; Vol. 2, Ch. 18, pp 649.

5. (a) Yang, D. Acc. Chem. Res. 2004, 37, 497. (b) Shi, Y. Acc. Chem. Res. 2004, 37, 488.

6. Jørgensen, K. A. Chem. Rev. 1989, 89, 431.

7. (a) Deng, L.; Furukawa, Y.; Martinez, L. E.; Jacobsen, E. N. Tetrahedron 1994, 50, 4323.

(b) Srinivasan, K.; Michaud, P.; Kochi, J. K. J. Am. Chem. Soc. 1986, 108, 2309.

8. Jacobsen, E. N. In Catalytic Asymmetric Synthesis; Ojima, I., Ed.; VCH: New York, 1993; p 159.

9. Hosoya, N.; Irie, R.; Ito, Y.; Katsuki, T. Synlett 1991, 691.

10. Sasaki, H.; Irie, R.; Hamada, T.; Suzuki, K.; Katsuki, T. Tetrahedron 1994, 50, 11827.

11. Chang, S.; Galvin, J. M.; Jacobsen, E. N. J. Am. Chem. Soc. 1994, 116, 6937.

12. Sun, Y.; Tang, N.; Liu, X. W.; Liu, W. S. Chin. Chem. Lett. 2004, 973.

13. Yang, S. Tang, N. J. Mol. Catal. A: Chem. 2006, 255(1-2), 171.

14. Daly, A. M.; Renehan, M. F.; Gilheany, D. G. Org. Lett. 2001, 3, 663.

15. Adolfsson, H.; Balan, D. In Aziridines and Epoxides in Organic Synthesis, Yudin, A. Ed.; Wiley-VCH: Weinheim, 2006; Ch. 6.

16. Nishiyama, H.; Shimida, T.; Itoh, H.; Sugiyama, H.; Motoyama, Y. Chem. Commun. 1997, 1863.

17. Tse, M. K.; Bhor, S.; Klawonn, M.; Anilkumar, G.; Jiao, H.; Spannenberg, A.; Doebler, C.; Maegerlein, W.; Hugl, H.; Beller, M. Chem. Eur. J. 2006, 12, 1875.

18. (a) Anilkumar, G.; Bhor, S.; Tse, M.K.; Klawonn, M.; Bitterlich, B.; Beller, M. Tetrahedron: Asymmetry 2005, 16, 3536. (b) Bhor, S.; Anilkumar, G.; Tse, M.K.; Klawonn, M.; Doebler, C.; Bitterlich, B.; Grotevendt, A.; Beller, M. Org. Lett. 2005, 7, 3393.

19. (a) Frohn, M.; Shi, Y. Synthesis 2000, 1979. (b) Shi, Y. Acc. Chem. Res. 2004, 37, 488. (c) Yang, D. Acc. Chem. Res. 2004, 37, 497.

20. Yang, D.; Wang, X.-C.; Wong, M.-K.; Yip, Y.-C.; Tang, M.-W. J. Am. Chem. Soc. 1996, $118,11311$.

21. Tong, Y.; Wang, Z.-X.; Shi, Y. J. Am. Chem. Soc. 1996, 118, 9806.

22. Wang, Z.-X.; Tu, Y.; Frohn, M.; Shi, Y. J. Org. Chem. 1997, 62, 2328.

23. Denmark, S.; Matsuhashi, H. J. Org. Chem. 2002, 67, 3479.

24. (a) Armstrong, A.; Hayter, B.R. Chem. Commun. 1998, 621. (b) Armstrong, A.; Hayter, B. R.; Moss, W. O.; Reeves, J. R.; Wailes, J. S. Tetrahedron: Asymmetry 2000, 11, 2057.

25. Sartori, G.; Armstrong, A.; Maggi, R.; Mazzacani, A.; Sartorio, R.; Bigi, F.; DominguezFernandez, B. J. Org. Chem. 2003, 68, 3232.

26. Armstrong, A.; Dominguez-Fernandez, B.; Tsuchiya, T. Tetrahedron 2006, 62, 6614. 
27. (a) Solladié-Cavallo, A.; Jierry, L.; Lupattelli, P.; Bovicelli, P.; Antonioletti, R. Tetrahedron 2004, 60, 11375. (b) Solladié-Cavallo, A.; Jierry, L.; Bouérat, L. Taillasson, P. Tetrahedron: Asymmetry. 2001, 12, 883.

28. Solladié-Cavallo, A.; Bouérat, L. Org. Lett. 2000, $2,3531$.

29. Solladié-Cavallo, A.; Diep-Vohuule, A.; Sunjic, V.; Vinkovic, V. Tetrahedron: Asymmetry 1996, 7, 1783.

30. Solladié-Cavallo, A.; Bouérat, L.; Roje, M. Tetrahedron Lett. 2000, 41, 7309.

31. Solladié-Cavallo, A.; Roje, M.; Isarno, T.; Sunjic, V.; Vinkovic, V. Eur. J. Org. Chem. 2000, 1077.

32. Aggarwal, V.; Bae, I.; Lee, H.-Y.; Richardson, J.; Williams, D. T. Angew. Chem. Int. Ed. 2003, 42, 3274.

33. Aggarwal, V. K.; Alonso, E.; Bae, I.; Hynd, G.; Lydon, K. M.; Palmer, M. J.; Patel, M.; Porcelloni, M.; Richardson, J.; Stenson, R. A.; Studley, J. R.; Vasse, J.-L.; Winn, C. L. J. Am. Chem. Soc. 2003, 125, 10926.

34. Vidal-Ferran, A.; Moyano, A.; Pericàs, M. A.; Riera, A. J. Org. Chem. 1997, 62, 4970.

35. Ringer, A. L.; Sinnokrot, M. O.; Lively, R. P.; Sherril, C. D. Chem. Eur. J. 2006, 12, 3821.

36. Chochrek, P.; Kurek-Tyrlik, A.; Michalak, K.; Wicha, J. Tetrahedron Lett. 2006, 47, 6017.

37. Flaherty, Y. M.; Gervay, J. Tetrahedron Lett. 1996, 37, 961.

38. Schultze, L. M.; Chapman, H. H.; Dubree, N. J.; Jones, R. J.; Kent, K. M.; Lee, T. T.; Louie, M. S.; Postich, M. J.; Prisbe, E. J.; Rohloff, J. C.; Yu, R. H. Tetrahedron Lett. 1998, 39, 1853.

39. Dragovich, P. S.; Prins, T. J.; Zhou, R. J. Org. Chem. 1995, 60, 4922.

40. Sajiki, H.; Hattori, K.; Hirota, K. Chem. Commun. 1999, 1041.

41. Ley, S. V.; Mitchell, C.; Pears, D.; Ramarao, C.; Yu, J.-Q.; Zhou, W. Org. Lett. 2003, 5, 4665.

42. Kwon, M. S.; Park, I. S.; Jang, J. S.; Lee, J. S.; Park, J. Org. Lett. 2007, 9, 3417.

43. Gansäuer, A.; Lauterbach, T.; Narayan, S. Angew. Chem. Int. Ed. 2003, 42, 5556.

44. Cuerva, J. M.; Campaña, A. G.; Justicia, J.; Rosales, A.; Oller-Lopez, J. L.; Robles, R.; Càrdenas, D. J.; Buñuel, E.; Oltra, J. E. Angew. Chem. Int. Ed. 2006, 45, 5522.

45. (a) Bolm, C.; Ewald, M.; Zehnder, M.; Neuburger, M. A. Chem. Ber. 1992, 125, 453. (b) Bolm, C.; Ewald, M. Tetrahedron Lett. 1990, 31, 5011. (c) Hawkins, J. M.; Sharpless, K. B. Tetrahedron Lett. 1987, 28, 2825.

46. Rüchardt, C.; Gärtner, H.; Salz, U. Angew. Chem. Int. Ed. 1984, 23, 162.

47. (a) Macedo, E.; Moberg, C. Tetrahedron: Asymm. 1995, 6, 549. (b) Nordström, K.; Macedo, E.; Moberg, C. J. Org. Chem. 1997, 62, 1604.

48. See Nishimura S. Handbook of Heterogenous Catalytic Hydrogenation for Organic Synthesis Wiley: New York, 2001; Ch. 13.1.2, p 575.

49. Lupattelli, P.; Bonini, C.; Di Blasio, N. In preparation.

50. Wen, Z.; Li, Z.;Shang, Z.; Cheng, J.-P. J. Org. Chem. 2001, 66, 1466. 
51. Smith, M. B.; March, J. Advanced Organic Chemistry $5^{\text {th }}$ Edn., Wiley-Interscience, 2001, Ch. 10, p 529.

52. Laxmi, Y. S.; Iyengar, D. S. Synth. Comm. 1997, 1731.

53. Ranu, B. C.; Das, A. R. J. Chem. Soc. Perkin Trans. I 1992, 1881.

54. Finkielsztein, L. M.; Aguirre J. M.; Lantaño, B.; Alesso, E. N.; Moltrasio Iglesias, G. Y. Synth. Commun. 2004, 34, 895.

55. Smith, W. B. J. Heterocycl. Chem. 1987, 24, 745.

56. Solladié-Cavallo, A.; Lupattelli, P.; Bonini, C. J. Org. Chem. 2005, 70, 1605.

57. Solladié-Cavallo, A.; Lupattelli, P.; Bonini, C.; Ostuni, V.; Di Blasio, N. J. Org. Chem. 2006, 71, 9891.

58. Bartoli, G.; Bosco, M.; Locatelli, M.; Marcantoni, E.; Melchiorre, P.; Sambri, L. Org. Lett. 2005, 7, 427.

59. Hayashi, Y.; Tamura, T.; Shoji, M. Adv. Synth. Catal. 2004, 346, 1106.

60. In a typical procedure, a $\mathrm{Mg}\left(\mathrm{ClO}_{4}\right)_{2} / \mathrm{H}_{2} \mathrm{O} 1: 10$ molar ratio was used.

61. (a) Righi, G.; Chionne, A.; D'Achille, R.; Bonini, C. Tetrahedron: Asymmetry 1997, 8, 903. (b) Bonini, C.; Righi, G. Synthesis 1994, 225.

62. Van Hylckama Vlieg, J. E. T.; Tang, L.; Lutjie Spelberg, J. H.; Smilda, T.; Poelarends, G. J.; Bosma, T.; Van Merode, A. E. J.; Fraajie, M. W.; Janssen, D. B. J. Bacteriol. 2001, 5058.

63. (a) Kasai, N.; Suzuki, T.; Furukawa, Y. J. Mol. Cat. B: Enzym. 1998, 4, 237. (b) Lutjie Spelberg, J. H.; van Hylckama Vlieg, J. E. T.; Bosma, T.; Kellog, R. M.; Janssen, D. B. Tetrahedron: Asymmetry 1999, 10, 2863.

64. Suzuki, T.; Kasai, N.; Minamiura, N. Tetrahedron: Asymmetry 1994, 5, 239.

65. Copley, S. D. Curr. Opin. Chem. Biol. 1998, 2, 613.

66. (a) See: Halohydrines and derivatives. In: Fiesers' Reagent for Organic Synthesis; Smith, J.G., Fieser, M., Eds.; New York, 1990. (b) Larock, R. C. Comprehensive Organic Transformations; VCH: New York, 1989; pp 508.

67. (a) Xu, L.-W.; Li, L.; Xia, C.-G.; Zhao, P.-Q. Tetrahedron Lett. 2004, 45, 2435. (b) Paek, S. H.; Shim, S. C.; Cho, C. S.; Kim, T.-J. Synlett 2003, 849. (c) Nakajima, M.; Saito, M.; Uemura, M.; Hashimoto, S. Tetrahedron Lett. 2002, 43, 8827.

68. (a) Soroka, M.; Goldeman, W.; Maysa, P.; Stochaj, M. Synthesis 2003, 2341. (b) Shargi, H.; Eskandari, M. M. Tetrahedron 2003, 59, 8509. (c) Shargi, H.; Paziraee, Z.; Nikman, K. Bull. Kor. Chem. Soc. 2002, 23, 1611. (d) Diaz, D.; Martin, T.; Martin, V. S. J. Org. Chem. 2001, 66, 7231.

69. (a) Roy, C. D.; Brown, H. C. J. Organomet. Chem. 2007, 692(7), 1608. (b) Ciaccio, J. A.; Heller, E.; Talbot, A. Synlett 1991, 248. (c) Joshi, N. N.; Srebnik, M.; Brown, H. C. J. Am. Chem. Soc. 1988, 110, 6246. (d) Guindon, Y.; Therien, M.; Girard, Y.; Yoakim, C. J. Org. Chem. 1987, 52, 1680.

70. (a) Sabitha, G.; Satheesh Babu, R.; Rajkumar, M.; Shrinivas Reddy, Ch.; Yadav, J. S. Tetrahedron Lett. 2001, 42, 3955. (b) Amantini, D.; Fringuelli, F.; Pizzo, F.; Vaccaro, L. J. 
Org. Chem. 2001, 66, 4463. (c) Kotsuki, H.; Shimanouchi, T. Tetrahedron Lett. 1996, 37, 1845 .

71. Stamatov, S. D.; Stawinski, J. Tetrahedron Lett. 2007, 48, 1887.

72. (a) Ranu, B. C.; Banerjee, S. J. Org. Chem. 2005, 70, 4517. (b) Yadav, J. S.; Reddy, B. V. S.; Srinivas Reddy, Ch.; Rajasekhar, K. Chem. Lett. 2004, 33, 476.

73. See: Righi, G.; Pescatore, G.; Bonadies, F.; Bonini, C. Tetrahedron 2001, 57, 5649 and references therein.

74. Ranu, B. C.; Jana, U. J. Org. Chem. 1998, 63, 8212.

75. (a) Bonini, C.; Giuliano, C.; Righi, G.; Rossi, L. Synth. Commun. 1992, 22, 1863. (b) Bonini, C.; Checconi, M.; Righi, G.; Rossi, L. Tetrahedron 1995, 51, 4111 and references therein. For application to the synthesis, see: (c) Federici, C.; Righi, G.; Rossi, L.; Bonini, C.; Chiummiento, L.; Funicello, M. Tetrahedron Lett. 1994, 35, 797. (d) Bonini, C.; Federici, C.; Rossi, L.; Righi, G. J. Org. Chem. 1995, 60, 4803.

76. (a) Righi, G.; Ronconi, S.; Bonini, C. Eur. J. Org. Chem. 2002, 1573. (b) Righi, G.; Chionne, A.; D'Achille, R.; Bonini, C. Tetrahedron: Asymmetry 1997, 8, 903. (c) Righi, G.; Rumboldt, G.; Bonini, C. J. Org. Chem. 1996, 61, 3557.

77. Lupattelli, P.; Bonini, C.; Caruso, L.; Gambacorta, A. J. Org. Chem. 2003, 68, 3360.

78. Solladié-Cavallo, A.; Lupattelli, P.; Marsol, C.; Isarno, T.; Bonini, C.; Caruso, L.; Maiorella, A. Eur. J. Org. Chem. 2002, 1439.

79. Guillermet, J.; Novak, A. J. Chim. Phys. 1970, 67, 982.

80. (a) Hancock, R. D. J. Chem. Educ. 1992, 69, 615-621. (b) Hancock, R. D. Acc. Chem. Res. 1990, 23, 253.

81. Solladié-Cavallo, A.; Lupattelli, P.; Bonini, C. J. Org. Chem. 2005, 70, 1605.

82. Smith, M. B. In March's Advanced Organic Chemistry V ${ }^{\text {th }}$ Ed., Smith, M.B.; March, J., Wiley-Interscience: New York, 2001; p 468.

83. Surendra, K.; Krishnaveni, N. S.; Nageswar, Y. V. D.; Rao, K. R. J. Org. Chem. 2003, 68, 4994.

84. (a) Ready, J. M; Jacobsen, E. N. J. Am. Chem. Soc. 1999, 121, 6086. (b) Matsunaga, S.; Das, J.; Roels, J.; Vogl, E. M.; Yamamoto, N.; Iida, T.; Yamaguchi, K.; Shibasaki, M. J. Am. Chem. Soc. 2000, 122, 2252.

85. Altenbach, H.-J., In: Comprehensive Organic Synthesis, Trost, B. M.; Fleming, I. Pergamon Press: New York, 1991; Vol. 6, Ch. 4.5, pp 847.

86. Fagnou, K.; Lautens, M. Org. Lett. 2000, 2, 2319.

87. Pineschi, M.; Bertolini, F.; Haak, R. M.; Crotti, P.; Macchia, M. Chem. Commun. 2005, 1426.

88. Han, J. H.; Hong, S. J.; Lee, E. Y.; Lee, J. H.; Kim, H. J.; Kwak, H.; Kim, C. Bull. Kor. Chem. Soc. 2005, 26, 1434.

89. Wu, W.; Liu, Q.; Shen, Y.; Li, R.; Wu, L. Tetrahedron Lett. 2007, 48, 1653.

90. Vyvyan, J. R.; Meyer, J. A.; Meyer, K. D. J. Org. Chem. 2003, 68, 9144. 
91. Tangestaninejad, S.; Habibi, M. H.; Mirkhani, V.; Moghadam, M. J. Chem. Res. (S) 2001, 365.

92. Mohammadpoor-Baltork, I.; Khosropour, A.; Aliyan, H. Synth. Commun. 2001, 31, 3411.

93. Iranpoor, N.; Zeynizadeh, B. J. Chem. Res. $(S)$ 1998, 466.

94. Adams, R. D.; Barnard, T. S.; Brosius, K. J. Organomet. Chem. 1999, 582, 358.

95. Iranpoor, N.; Kazemi, F. Synth. Commun. 1998, $28,3189$.

96. Zhu, Z.; Espenson, J. H. Organometallics 1997, 16, 3658.

97. (a) Lee, S.-H.; Lee, J.-C.; Li, M.-N.; Kim, N.-S. Bull. Kor. Chem. Soc. 2005, 26, 221. (b) Krasik, P.; Bohemien-Bernard, M.; Yu, Q. Synlett 2005, 854.

98. Procopio, A.; Dalpozzo, R.; De Nino, A.; Maiuolo, L.; Nardi, M.; Russo, B. Adv. Synth. Catal. 2005, 347, 1447.

99. Concellón, J. M.; Suarez, J. R.; Garcia-Granda, S.; Diaz, M. R. Org. Lett. 2005, 7, 247.

100.Kazemi, F.; Kiasat, A. R.; Ebrahimi, S. Synth. Commun. 2005, 35, 1441.

101.He, J.-Y; Gao, F.-X.; Hua, R.-M. Chin. J. Chem. 2005, 23, 1275.

102.Solladié-Cavallo, A.; Choucair, E.; Balaz, M.; Lupattelli, P.; Bonini, C.; Di Blasio, N. Eur. J. Org. Chem. 2006, 3007.

\section{Authors' biographical data}

Carlo Bonini was born in Rome (Italy) in 1948. He graduated in the University "La Sapienza" in Rome in 1972. Then he spent eight years as doctoral fellow in the same University, working on isolation, structural elucidation and modification of natural products, associated to the italian CNR Centre of Natural Product Chemistry. Then he became a Research Associate in 1980 in Rome. In 1982 he was awarded of a CNR fellowship and he spent one year at Stanford University in the Professor Carl Djerassi's group. In 1987 he moved as Associate Professor to the University of Basilicata (Potenza, Italy), where he became Full Professor of Organic Chemistry in 1994. His research interest is focused on the enantioselective synthesis of natural products and pharmaceuticals (via original chemical or biocatalytic routes) as well as on the reactivity of three membered heterocycles such as epoxides and aziridines.

Paolo Lupattelli was born in Rome (Italy) in 1965. He graduated in Industrial Chemistry at the University "La Sapienza" in Rome in 1990 and got PhD degree in Organic Chemistry at the same University in 1994, working on Dioxiranes in the chemistry of steroidal compounds. Then he was awarded of a CNR 1 year fellowship in the Centre of Natural Product Chemistry. In 1995 he spent one year as post doc (awarded by D.A.A.D. and University "La Sapienza" fellowship) at the University of Paderborn (Germany), in the Professor Karsten Krohn's group. In 1996 he moved as Research Associate to the University of Basilicata (Potenza, Italy). Between 2002 and 2003 he was appointed as Associate Researcher (Chercheur Associé) by french CNRS (6 months, overall), in dr. Arlette Solladié-Cavallo's research group, ECPM, Université Louis 
Pasteur, Strasbourg (France). His research interest is focused on new methods of stereoselective functionalization for the synthesis of enantiopure compounds with high molecular recognition capacity, chemo-, regio- and diastereoselective ring opening reactions of epoxides, asymmetric synthesis of pharmaceuticals, chemo- and stereoselective oxidation methods with chiral and achiral dioxiranes. 